\title{
Molecular phylogeny, morphology and bioacoustics reveal five additional species of arboreal microhylid frogs of the genus Anodonthyla from Madagascar
}

\author{
Miguel Vences ${ }^{1,5}$, Frank Glaw², Jörn Köhler ${ }^{3}$, Katharina C. Wollenberg ${ }^{1,4}$ \\ ${ }^{1}$ Zoological Institute, Technical University of Braunschweig, Spielmannstr. 8, 38106 Braunschweig, Germany \\ ${ }^{2}$ Zoologische Staatssammlung München, Münchhausenstr. 21, 81247 München, Germany \\ ${ }^{3}$ Department of Natural History - Zoology, Hessisches Landesmuseum Darmstadt, Friedensplatz 1, 64283 \\ Darmstadt, Germany \\ ${ }^{4}$ Department of Organismic and Evolutionary Biology \& Museum of Comparative Zoology, Harvard University, \\ Cambridge, MA 02138, USA \\ ${ }^{5}$ E-mail:m.vences@tu-bs.de
}

Key words: Amphibia, Anura, Cophylinae, integrative taxonomy, Microhylidae, new species

\begin{abstract}
We provide a partial revision of the microhylid frogs of the genus Anodonthyla, endemic to Madagascar, based on comprehensive molecular, bioacoustic and morphological data sets that include newly collected specimens from multiple localities. The molecular trees provide strong evidence for the polyphyly of several nominal species as they were previously defined, especially of Anodonthyla boulengeri and A. nigrigularis. As a consequence, we here resurrect the nomen Mantella pollicaris Boettger as Anodonthyla pollicaris from the synonymy of $A$. boulengeri, and we describe four new species, all with strong genetic divergences to other nominal species: Anodonthyla emilei from Ranomafana National Park, a comparatively medium-sized species characterized by a multi-note advertisement call with high note repetition rate; $A$. theoi from Manombo Special Reserve, a small species characterized by low note repetition rate, long note duration and high spectral call frequency; $A$. vallani, a medium-sized species from Ambohitantely Special Reserve, characterized by low note repetition rate, long note duration and low spectral call frequency; and A. jeanbai, a small species from Andohahela National Park, characterized by a long and narrow head, presence of short dorsolateral folds, a very short first finger, and a yellowish ventral colour. A further candidate species comprises populations previously assigned to $A$. boulengeri from the Ranomafana region, which we do not describe because the corresponding data set is too fragmentary, and we refer to it as A. sp. aff. boulengeri 'Ranomafana'. The molecular phylogeny indicates recurrent shifts between high and low note repetition rates in calls, based mainly on three strongly supported sister groups: A. moramora with low repetition rate and $A$. nigrigularis with moderately low repetition rate; A. theoi with low repetition rate and A. pollicaris with high repetition rate; and A. vallani with low repetition rate and $A$. sp. aff. boulengeri 'Ranomafana' with high repetition rate. The two species with the northernmost ranges, A. hutchisoni and A. boulengeri, are phylogenetically nested within clades of species occurring further south, confirming that the center of origin of the genus Anodonthyla was most likely in the South East of Madagascar.
\end{abstract}

\section{Contents}

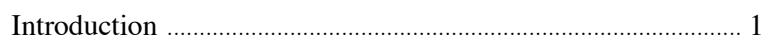

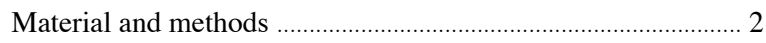

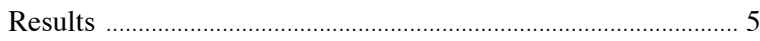

Molecular diversity and phylogenetic relationships of

Anodonthyla ……........................................................... 5

Bioacoustic and morphological differentiation of

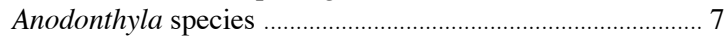

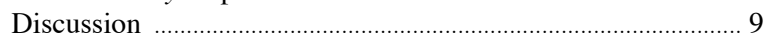

Species diversity in Anodonthyla ……………................. 9

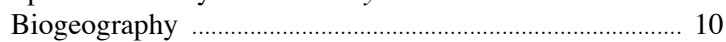

Evolution of calls in Anodonthyla ........................................ 11

Conservation and IUCN red list assessment ..................... 11

Acknowledgements ............................................................... 12

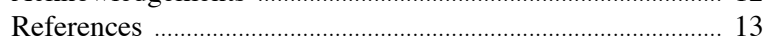

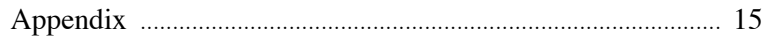

\section{Introduction}

Frogs of the family Microhylidae Günther, 1859 are among the most poorly known amphibian groups. Several factors contribute to the difficulty of their study: some species have a very seasonal breeding behaviour and are thus difficult to find, other species are minute in body size and therefore often overlooked. The high frequency of evolutionary change in some osteological characters, especially reductions in the shoulder girdle, has led to the definition of a large number of microhylid genera containing only one or a few species, and phylogenetic relationships among genera and among major microhylid clades have long remained enigmatic. Recently, molecular data have started to decipher microhylid diversity and relationships. Studies of multigene datasets have produced 
the first comprehensive phylogenies of major microhylid lineages (Van der Meijden et al., 2004, 2007; Van Bocxlaer et al., 2006) although several basal relationships remained unclarified. Phylogenies based on dense taxon sampling of microhylids from New Guinea (Köhler and Günther, 2008) and Madagascar (Andreone et al., 2005b; Wollenberg et al., 2008) provided evidence for a high proportion of undescribed diversity, with many candidate species exhibiting high genetic divergence to all known species.

In Madagascar, microhylids are represented by three subfamilies: the Dyscophinae Boulenger, 1882 with one genus and three species, the Scaphiophryninae Laurent, 1946 with two genera and ten species, and the Cophylinae Cope, 1889 with seven genera and 45 species (Glaw and Vences, 2007; Fenolio et al., 2007). Molecular data indicate that scaphiophrynines and cophylines together form a clade that is endemic to Madagascar and has unclarified relationships to other microhylids, whereas dyscophines form a separate evolutionary lineage related to Asian microhylids (Van der Meijden et al., 2007). Although new species of scaphiophrynines have been discovered in the last years (e.g. Glos et al., 2005; Andreone et al., 2006), the bulk of undescribed microhylid diversity in Madagascar is found in the Cophylinae (Wollenberg et al., 2008; Vieites et al., 2009).

Cophylines are characterized by a derived mode of larval development: whereas most microhylids have a specialized filter-feeding tadpole, cophylines have non-feeding tadpoles that develop either in tree holes, terrestrial foam nests, or terrestrial jelly nests (Blommers-Schlösser, 1975; Glaw and Vences, 2007; Grosjean et al., 2007). Most cophylines have very simple advertisement calls, consisting of single melodious notes that are repeated after regular intervals and for long periods of time, usually lasting several minutes. Correlated to the reproductive mode of the various cophyline lineages is their arboreal versus terrestrial or fossorial ecology, and apparently, multiple evolutionary shifts between arboreal and terrestrial habits have occurred in this subfamily (Andreone et al., 2005b).

One of the arboreal lineages in the Cophylinae is the genus Anodonthyla Müller, 1892 which is a welldefined monophyletic group based on both molecular and morphological characters (Blommers-Schlösser and Blanc, 1991; Andreone et al., 2005b; Aprea et al., 2007; Wollenberg et al., 2008). One of the most obvious morphological synapomorphies of the genus is the presence, in males only, of a large prepollex that runs along the first finger and generally is closely connected to the first finger over most of its length. Correlated to this character, in males and females, the first finger is very short compared to other cophylines.

Anodonthyla at present comprises six species (Blommers-Schlösser, 1975; Blommers-Schlösser and Blanc, 1991; Glaw and Vences, 2005, 2007; Fenolio et al., 2007), of which five are arboreal species that breed, as far as known, in holes of tree or bamboo trunks: Anodonthyla boulengeri Müller, 1892; A. hutchisoni Fenolio, Walvoord, Stout, Randrianirina, and Andreone, 2007; A. moramora Glaw and Vences, 2005; A. nigrigularis Glaw and Vences, 1992; A. rouxae Guibé, 1974. In contrast, Anodonthyla montana Angel, 1925 appears to be restricted to areas of the granitic Andringitra massif above the tree line and here breeds in small rock cavities. However, preliminary data already indicated that these species numbers are underestimations since the available molecular and bioacoustic evidence pointed to several highly divergent genealogical lineages within A. boulengeri, and to geographically highly distant populations within A. nigrigularis that warranted further taxonomic study (Vallan, 2000; Glaw and Vences, 2005, 2007; Fenolio et al., 2007). Here we present a survey of molecular variation based on mitochondrial genes, in combination with bioacoustic and morphological data from new Anodonthyla collections mainly obtained through intensive fieldwork over the past five years. Based on these data we conduct a partial revision of the genus that leads to the description of four new species and the resurrection of one further species from synonymy.

\section{Material and methods}

Specimens were collected at night by opportunistic searching and localizing calling males, using torches and head lamps. They were euthanized in a chlorobutanol solution, fixed in $95 \%$ ethanol or $7 \%$ formalin, and preserved in $70 \%$ ethanol. Locality information was recorded with GPS receivers. Specimens studied in this paper are deposited in the collections of the Muséum National d'Histoire Naturelle, Paris (MNHN), Naturhistorisches Museum Basel (NMBA), Forschungsinstitut und Naturmuseum Senckenberg, Frankfurt (SMF), Université d'Antananarivo, Département de Biologie Animale, Antananarivo (UADBA), Zoologisches Forschungsmuseum Alexander Koenig, Bonn (ZFMK), Zoölogisch Museum Amsterdam (ZMA), and the Zoologische Staatssammlung 
München (ZSM). FGMV, FGZC and ZCMV refer to F. Glaw and M. Vences field numbers, respectively; FAZC refers to F. Andreone field numbers. MRSN is used as acronym for the Museo Regionale di Scienze Naturali di Torino. Terminology for biogeographic regions of Madagascar follows Boumans et al. (2007) (see also Glaw and Vences, 2007).

Morphology. Morphological measurements (in millimetres) were all taken by M. Vences with digital callipers (precision $0.01 \mathrm{~mm}$ ) to the nearest $0.1 \mathrm{~mm}$. Used abbreviations are: SVL (snout-vent length), HW (greatest head width), HL (head length), ED (horizontal eye diameter), END (eye-nostril distance), NSD (nostril-snout tip distance), NND (nostril-nostril distance), TD (horizontal tympanum diameter), PREP (prepollex length), TL (tibia length), HAL (hand length), HIL (hindlimb length), FL (foot length), FOTL (foot length including tarsus), FORL (forelimb length), and RHL (relative hindlimb length). Terminology and description scheme follow Glaw and Vences (2005) and Glaw and Vences (1997) for eye colouration. Morphological differentiation was analyzed by computing residuals of all morphological variables except TD (for which data are incomplete) to SVL, and the obtained residuals were submitted to a Principal Component Analysis (PCA) in STATISTICA (StatSoft, Tulsa, Oklahoma, USA). We then plotted values of the Principal Component with highest Eigenvalue against SVL, and the ratio of the residuals of HW and HL to infer morphological differentiation among Anodonthyla species.

Bioacoustics. Calls were recorded in the field using different types of tape recorders (Sony WM-D6C, Tensai RCR-3222) and external microphones (Sennheiser Me-80, Vivanco EM 238), or with an Edirol R-09 24bit digital recorder with internal microphone and saved as uncompressed files. Recordings were sampled (or re-sampled) at $22.05 \mathrm{kHz}$ and 16-bit resolution and computer-analysed using the software CoolEdit98. Frequency information was obtained through Fast Fourier Transformation (FFT; width 1024 points). Spectrograms were obtained at Hanning window function with 256 bands resolution. Temporal measurements are given as range, with mean \pm standard deviation in parentheses. Terminology in call descriptions follows Köhler et al. (2005a).

Molecular phylogeny. In order to provide information on the genetic homogeneity of species and their phylogeny, we assembled two molecular data sets. (1) For DNA barcoding purposes, we sequenced for a data set of 63 Anodonthyla specimens a fragment of the mitochondrial 16S rRNA gene, using primers 16SL3 and 16SAH as in Vences et al. (2003). The final alignment contained 500 nucleotide positions. We computed a Bayesian inference tree using MrBayes V.3.1.2. (Ronquist and Huelsenbeck, 2003) and a Maximum Likelihood bootstrap tree using the RaxML server (Stamatakis et al. 2008), following detailed protocols for selection of substitution models as described below. (2) To reliably assess the phylogenetic relationships among Anodonthyla species, we compiled a multi-gene dataset comprising one specimen for all nominal species and for most of the previously identified genetically divergent lineages of $\mathrm{An}$ odonthyla. A dataset of $16 \mathrm{~S}$ and $12 \mathrm{~S}$ rRNA and cytochrome $b$ gene sequences for most of these was available from Wollenberg et al. (2008). We complemented this data set for a number of additional individuals using primers and protocols as in Vences et al. (2003) and Wollenberg et al. (2008), and added partial sequences of the cytochrome oxidase subunit I using standard barcoding protocols and primers (Hebert $e t$ al., 2003). Altogether we assembled a concatenated dataset of 3187 basepairs, being comprised of 700 basepairs of the mitochondrial 12S rRNA gene, of two fragments of the 16S rRNA gene (539 and 737 $\mathrm{bp}$, respectively), and of each a fragment of the mitochondrial cytochrome b (cob, 574 bp) and cytochrome oxidase subunit I (cox1, $637 \mathrm{bp}$ ) genes (for Genbank accession numbers of most sequences see Wollenberg et al., 2008; accession numbers are GU048760-GU048808 and GU177051-GU177078 for newly determined sequences). A sequence of the dyscophine species Dyscophus antongilii was added as outgroup taxon, and the cophyline species Platypelis grandis and Stumpffia gimmeli were added to the dataset to obtain hierarchical outgroups. Congruence of single-gene phylogenetic topologies was verified by comparing Neighbor-joining trees before computing a phylogeny from the concatenated dataset. For the concatenated dataset, the best-fit model of evolution was inferred using the FINDMODEL online interface of the HIV database (accessible via http:// www.hiv.lanl.gov/content/sequence/findmodel/findmodel.html).

Phylogenies were constructed using Bayesian inference (using MrBayes V.3.1.2., Ronquist and Huelsenbeck, 2003, with 3.2 million generations), Maximum Likelihood using the online interface of PhyML (Guindon and Gascuel, 2003), and Maximum Parsimony using PAUP* (V. 4.0.b10, Swofford, 2002), with 2000 (ML) and 1000 (MP) bootstrap replicates. 


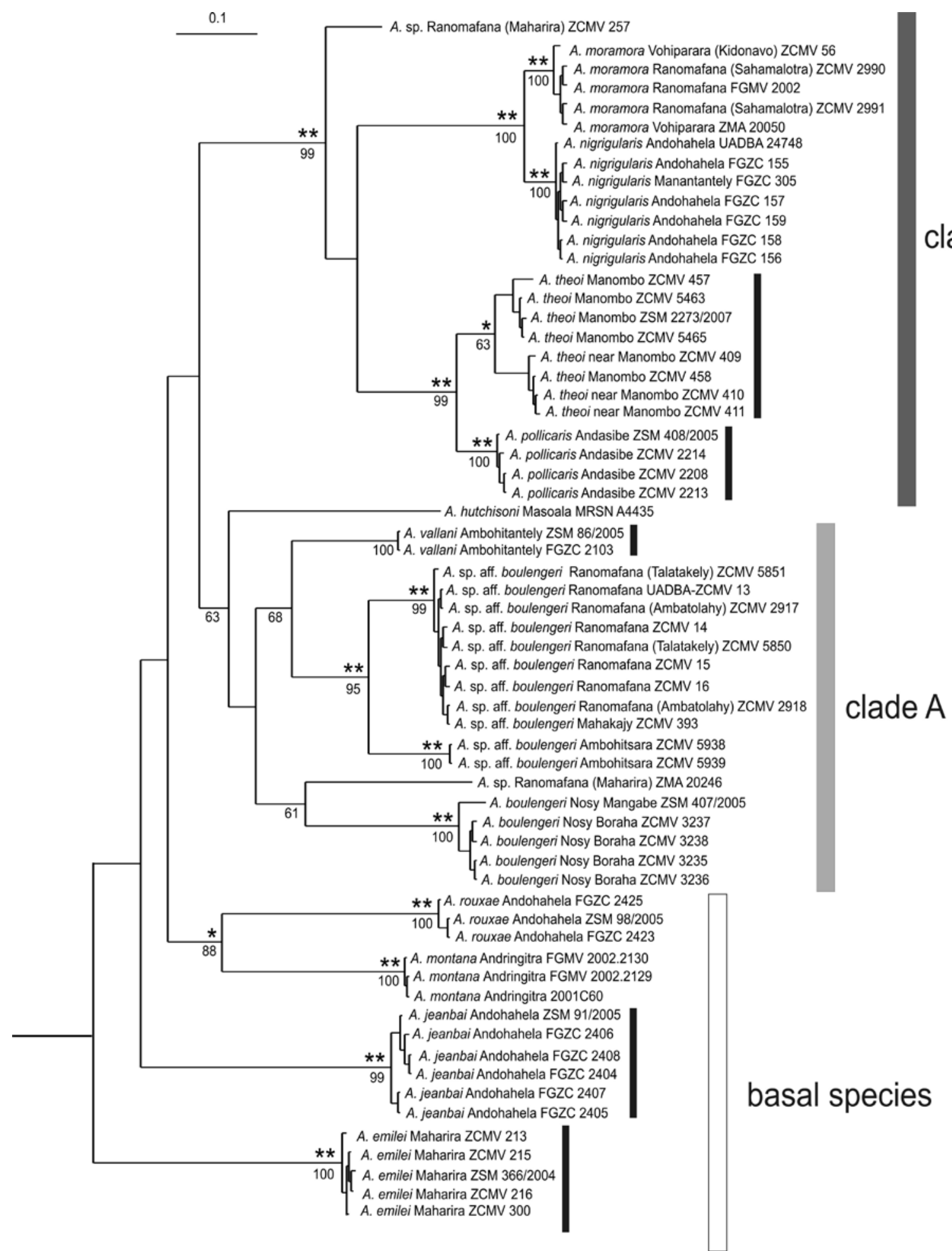

Fig. 1. Phylogenetic tree of Anodonthyla species based on Bayesian Inference analysis of partial sequences of the 16S rRNA gene (500 bp). Dyscophus antongilii (Dyscophinae) was used as outgroup. Black bars mark species newly described or revalidated in the present paper (Appendix). Asterisks and numbers show nodal support from Bayesian posterior probabilities $(* \geq 0.95$, ** $\geq 0.99$ ), and Maximum Likelihood bootstrap analysis (not shown if posterior probability $<95$ or bootstrap values $<50$ ). 


\section{Results}

Molecular diversity and phylogenetic relationships of Anodonthyla

The tree based on 16S sequences as reproduced in Fig. 1 reveals the presence of numerous deep genealogical lineages within Anodonthyla. Most of the populations studied were strongly differentiated but specimens from the same populations were genetically very similar or had identical haplotypes. The tree based on concatenated sequences of four mitochondrial genes (Fig. 2) corroborates most of the phylogenetic relationships suggested by the 16S rRNA tree and provides a better phylogenetic resolution, although several basal relationships remain unresolved. Exploratory separate analyses of each of the gene fragments yielded concordant results (not shown).

The results support the monophyly of the genus Anodonthyla (Fig. 2) and clearly define genetically all nominal species of the genus although a redefinition of two of these, A. boulengeri and A. nigrigularis, becomes necessary.

In the following we review the identity of the various genetically homogeneous clades as identified in
Fig. 1 and their phylogenetic relationships as recovered by the combined analysis (Fig. 2).

According to the multi-gene analysis (Fig. 2) two well-defined and described species occurring in highelevation habitats of south-eastern Madagascar, $A$. montana and $A$. rouxae, form a monophyletic group and are placed in a basal position in Anodonthyla. The next most basal clade (but placed as most basal clade in Fig. 1) is made up by a large species from various localities in Ranomafana National Park which has a unique advertisement call and is described herein as Anodonthyla emilei (Appendix).

A second strongly divergent species that occupies a basal position in both trees (Figs 1-2) is made up by small-sized specimens from high elevations in Andohahela National Park in south-eastern Madagascar. These specimens show subtle but constant differences to other Anodonthyla in morphology and colouration (see below) and are herein described as A. jeanbai (Appendix).

The remaining Anodonthyla are grouped in two major clades. The first of these (here named clade A) contains specimens that we assign to A. boulengeri (from the central east coast of Madagascar: Nosy Boraha and Nosy Mangabe) as well as A. hutchisoni. The

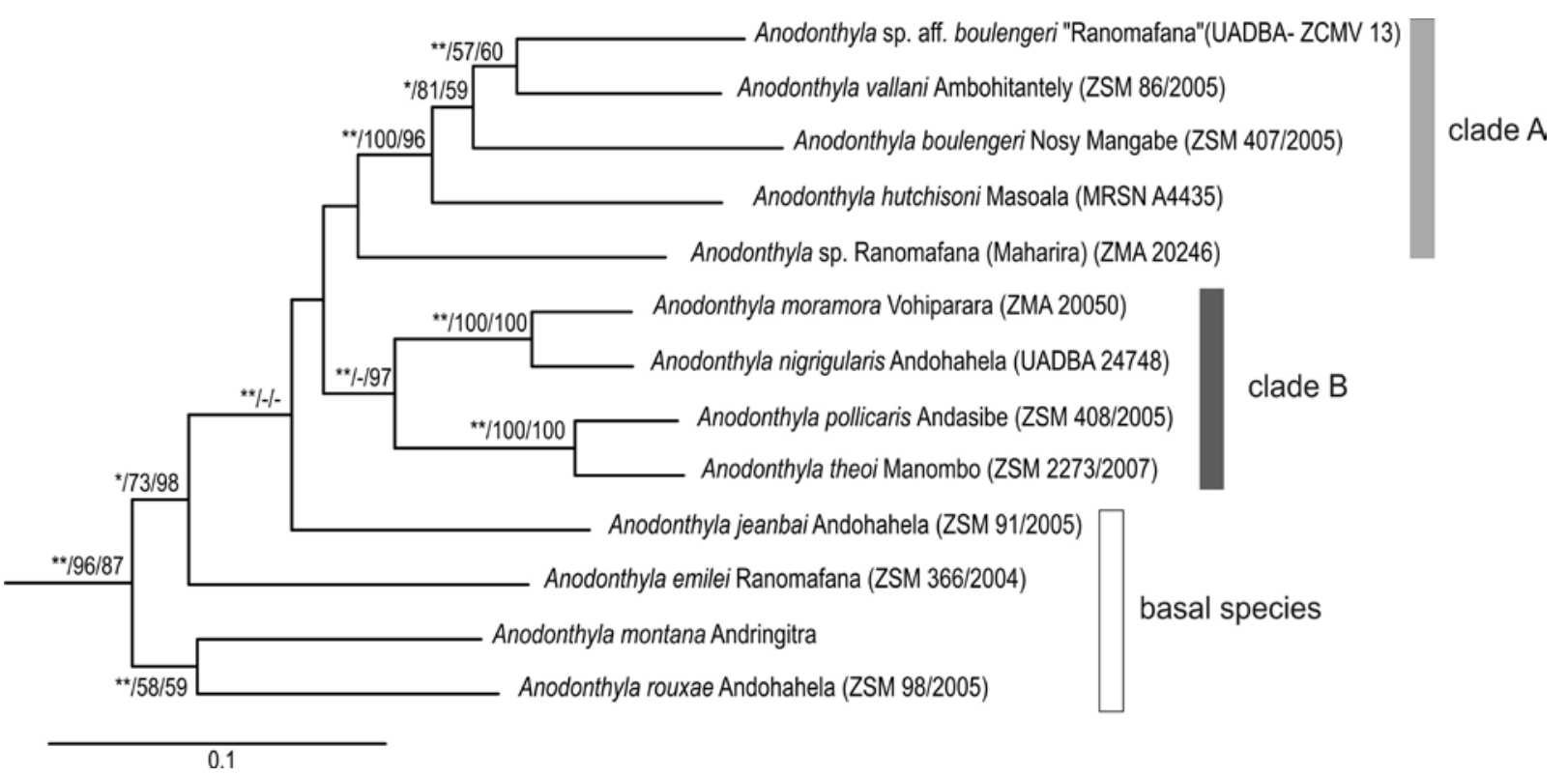

Fig. 2. Phylogenetic tree of Anodonthyla species based on Bayesian Inference analysis of the concatenated sequences of $12 \mathrm{~S}$ rRNA, $16 \mathrm{~S}$ rRNA, cytochrome $b$ and cytochrome oxidase subunit I sequences (3187 bp). Dyscophus antongilii (Dyscophinae) was used as outgroup, Stumpffia gimmeli and Platypelis grandis (Cophylinae) were included as hierarchical outgroups (not shown). Asterisks and numbers show nodal support from Bayesian posterior probabilities $(* \geq 0.95, * * \geq 0.99)$, and Maximum Likelihood and Maximum Parsimony bootstrap analysis (not shown if posterior probability $<95$ or bootstrap values $<50$ ). 
populations of $A$. boulengeri (also including one specimen from Foulpointe, not shown in Fig. 1) have a pairwise $16 \mathrm{~S}$ divergence of 1.1-1.6\%. Furthermore, this clade contains several deeply differentiated genealogical lineages: (1) Specimens from Ambohitantely which in morphology and advertisement calls are closer to A. nigrigularis than to A. boulengeri; these are herein described as A. vallani (Appendix). (2) Specimens from the Ranomafana area (Ranomafana, Mahakajy, Ambohitsara) that by morphology and advertisement call superficially resemble A. boulengeri, although small but constant bioacoustic differences are evident. Interestingly, specimens from the locality Ambohitsara show a pronounced genetic divergence to those from Ranomafana and Mahakajy. We refer to these specimens here as $A$. sp. aff. boulengeri 'Ranomafana' and refrain from a formal species de-

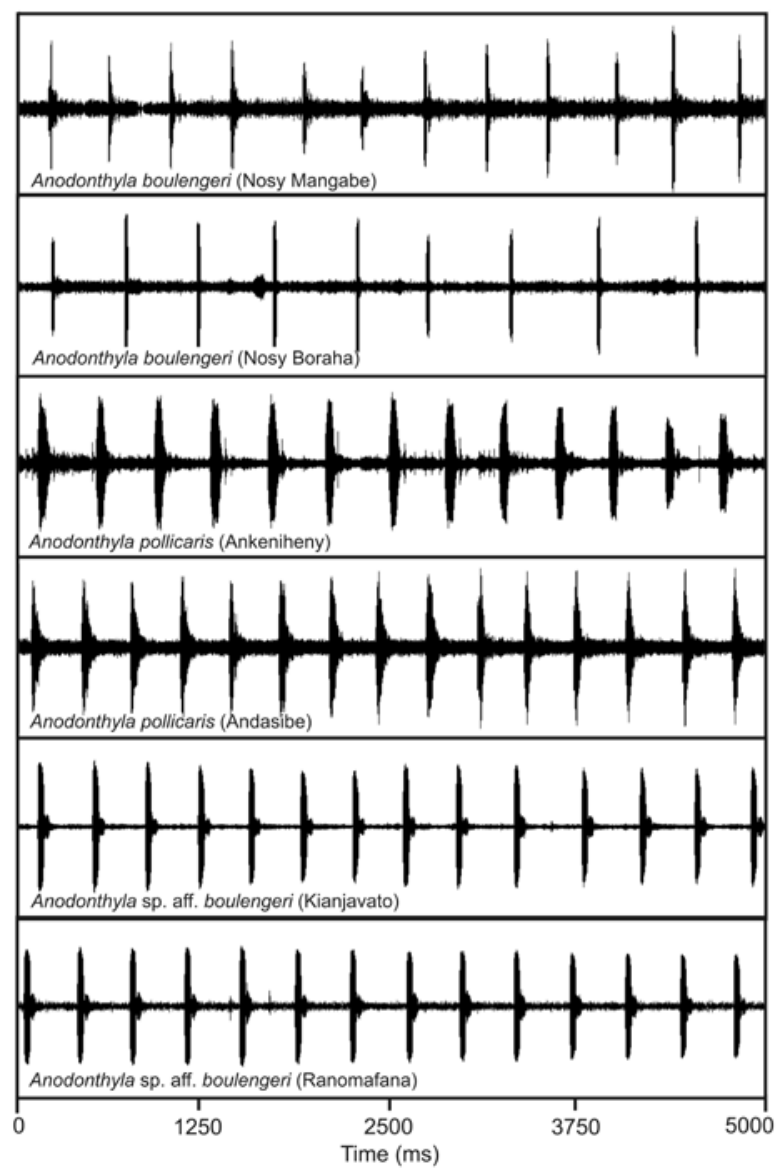

Fig. 3. Comparative waveforms of parts of call series of Anodonthyla boulengeri, A. pollicaris, and A. sp. aff. boulengeri 'Ranomafana' at same time scale. For details of localities and recording dates, see Table 3 . scription until more in-depth analyses on these populations become available (Appendix). (3) One specimen (ZMA 20246) is genetically distinct and probably represents a further undescribed species from the Ranomafana area, but no further data are available for this individual.

The second major clade within Anodonthyla (clade B) contains specimens of A. nigrigularis and A. moramora which are sister species with high support. These two species have a relatively low genetic divergence of $2.0 \%$ in the $16 \mathrm{~S}$ rRNA gene. Furthermore this clade contains (1) specimens from Andasibe that previously were considered to be A. boulengeri but are placed sister to (2) a species from Manombo in the south-east that distinctly differs from other Anodonthyla in advertisement calls. We here resurrect the name A. pollicaris for the Andasibe population and

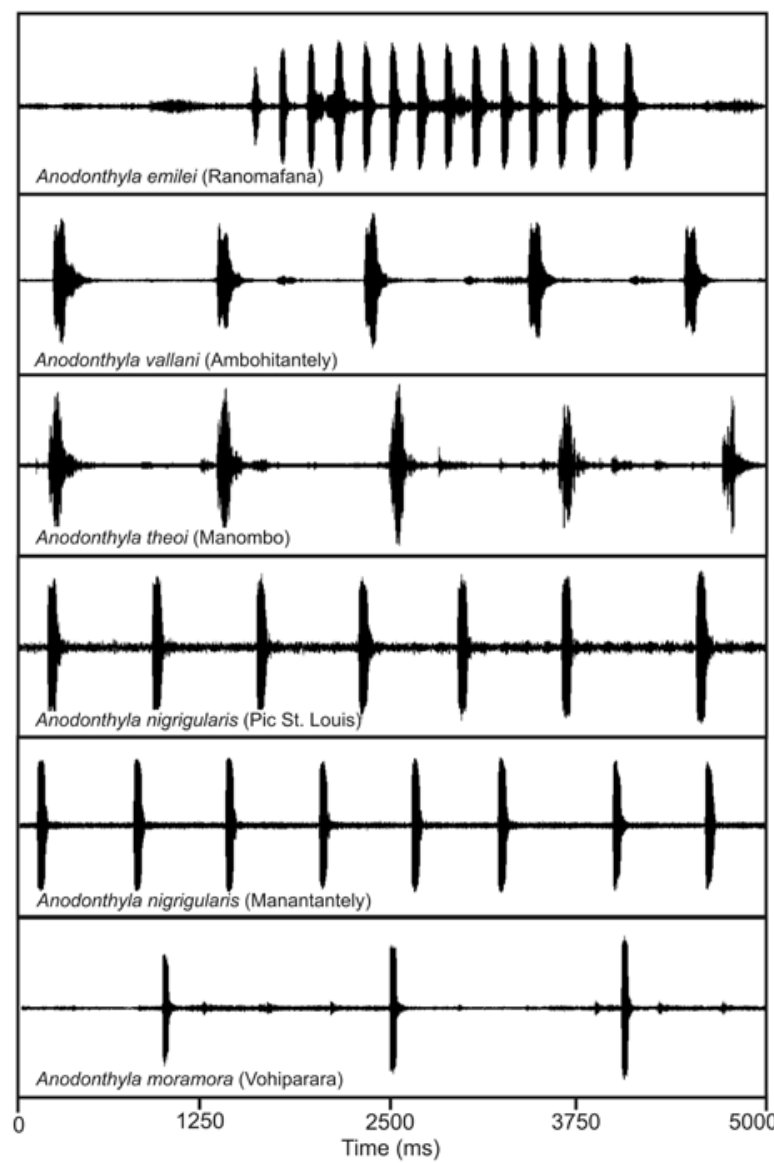

Fig. 4. Comparative waveforms of parts of call series of Anodonthyla emilei, A. vallani, A. theoi, A. nigrigularis, and A. moramora at same time scale. For details of localities and recording dates, see Table 3 . 
describe the Manombo population as a new species, $A$. theoi (16S divergence between these two species: $3.5 \%$; Appendix). Finally, this clade contains (3) a further isolated specimen from the Ranomafana area (ZCMV 257) that probably represents an undescribed species but for which no further data are available.

Bioacoustic and morphological differentiation of Anodonthyla species

The molecular data (Figs 1-2) indicate that several species as previously understood (e.g. Glaw and Vences, 1994) in fact probably represent complexes of various species. Because our molecular data set includes only mitochondrial genes we cannot use the criterion of congruence of various unlinked loci (i.e., following the genealogical concordance method of phylogenetic species recognition, GCPSR; Avise and Ball, 1990) to define species of Anodonthyla and need to take into account the possibility that some of the unexpected phylogenetic relationships may be due to introgression.

However, a detailed comparison of bioacoustic and morphological data indicates that in almost all cases the mitochondrial lineages identified are congruent with these independent taxonomic characters.

Advertisement calls, as represented by oscillograms in Figs 3-4 and described in detail in the Appendix, allow to easily separate various forms discovered by the molecular analysis, and to corroborate their status as distinct species. Anodonthyla emilei has a unique call consisting of a rapid note series rather than regularly repeated single notes. Calls of $A$. vallani and $A$. theoi differ by their slow note repetition rate, with values intermediate those of $A$. $n i$ grigularis and A. moramora, from all other species; and calls of $A$. theoi can be distinguished by a distinctly higher spectral frequency from those of $A$. vallani (Appendix). Furthermore, among the species with rapid note repetition rate, it is possible to distinguish $A$. boulengeri by its very short note duration from A. pollicaris; although subtle, this difference is constant across localities and easily measurable. Hence, except for A. jeanbai whose calls are unknown, all species newly described or revalidated herein have a bioacoustic differentiation concordant with their molecular differentiation.

Morphological data yielded a number of additional taxonomic characters to differentiate some of the newly discovered species. Most importantly, A. jeanbai for which bioacoustic data are lacking can be recognized

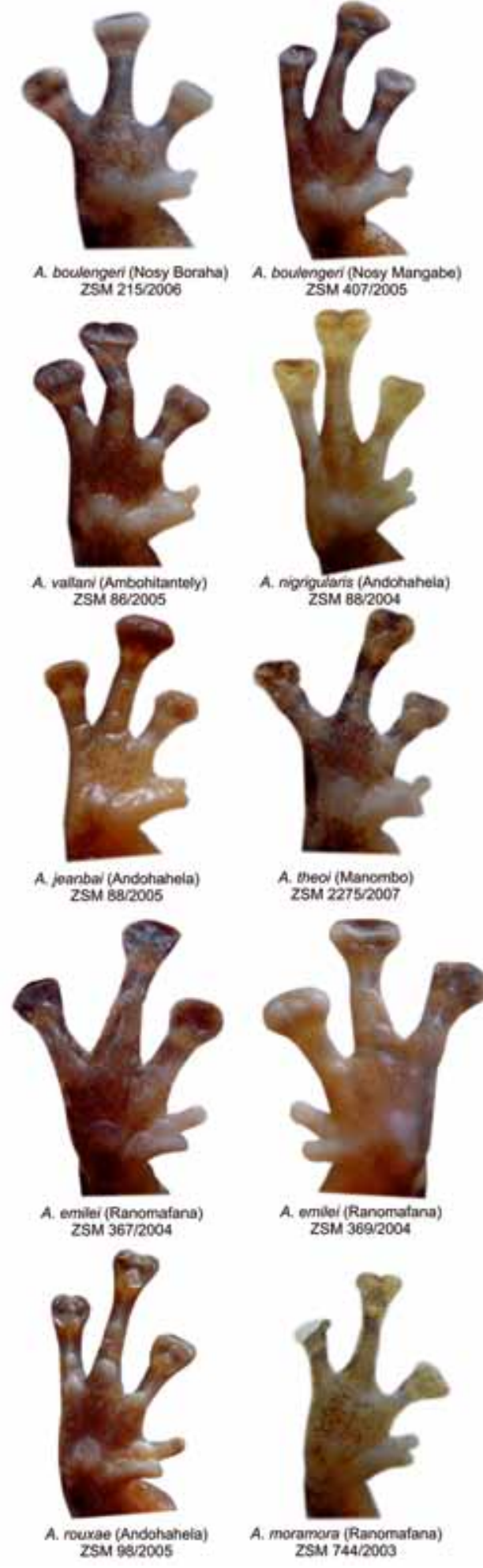

Fig. 5. Views of palmar surfaces of males of various Anodonthyla species, showing relative size and degree of separation of first finger and prepollex. Not to scale. 

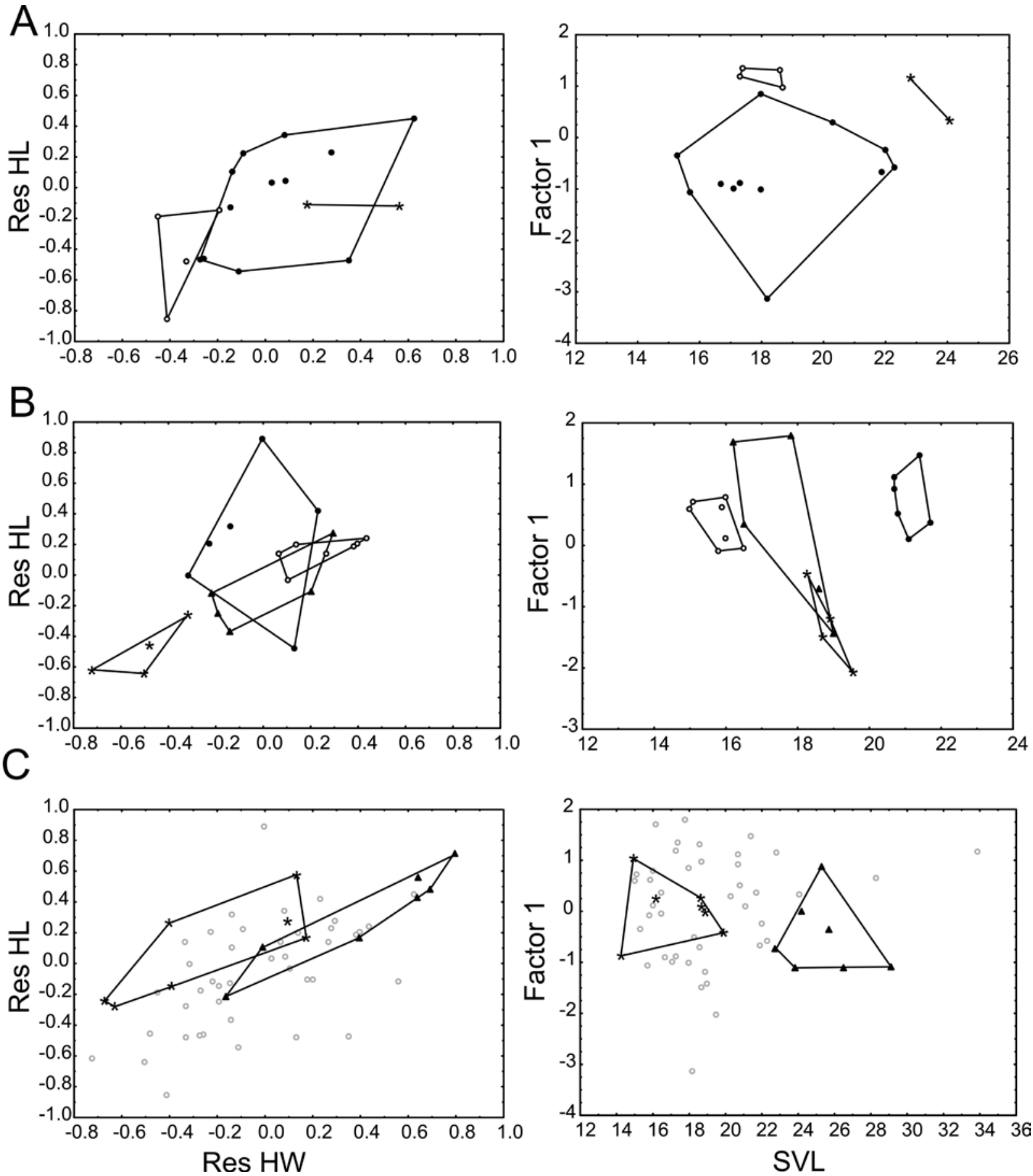

Fig. 6. Morphometric differentiation of the nine species with respect to their phylogenetic position (data see Table 2). A - A. vallani (asterisks), A. boulengeri (filled dots), A. sp. aff. boulengeri 'Ranomafana' (empty dots). B - A.theoi (asterisks), A.pollicaris (triangles), A. nigrigularis (filled dots), A. moramora (empty dots). C - A. jeanbai (asterisks), A. emilei (triangles), all other specimens (empty circles). 
by a yellowish ventral side (only shared with $A$. moramora), presence of a short tubercular dorsolateral fold posterior to the eye, and an extremely short first finger (shorter than prepollex; Fig. 5). A. emilei differs from most other species by its large size in combination with a rather tubercular dorsal skin. For further diagnostic characters, see Appendix.

Morphometric data can further be used to distinguish several of those species that by the molecular data are placed phylogenetically close to each other. The PCA of the residuals of the morphological variables yielded four factors with Eigenvalues $<1$ in Varimax-raw rotated coordinate system (explaining 33\%, 16.9\%, 9.9\%, and $7.8 \%$ of total variance, respectively). The factor with highest Eigenvalue received high factor loadings from the variables HIL, FOTL, FL, TIBL and RHL and was found to be useful in differentiating Anodonthyla species together with SVL, as well as the ratio of the residuals of HW and HL (ResHW/ResHL) (Fig. 6). In the molecular clade containing $A$. sp. aff. boulengeri 'Ranomafana' as sister to A. vallani and A. boulengeri all three species can be well distinguished according to both their factor1/SVL and ResHW/ResHL ratios (Fig. $6 a)$. In the well-supported clade containing the two sister species pairs A. pollicaris and A. theoi, and A. moramora and $A$. nigrigularis, the latter pair can be distinguished by their factor 1/SVL ratio. Although A. pollicaris and $A$. theoi have overlapping factor1/SVL ratios, their ResHW/ResHL ratios are non-overlapping (Fig. 6b). The phylogenetic placement of the other two newly described Anodonthyla species, A. jeanbai and A. emilei, is not well resolved. Although their ResHW/ ResHL ratios are overlapping, they can be morphologically well distinguished with their factor $1 / \mathrm{SVL}$ ratio (Fig. 6c). No clear distinction was possible between $A$. boulengeri and $A$. pollicaris by morphometry (not shown), largely due to the high variability of $A$. boulengeri and relatively low sample sizes for both species.

Summarizing, there are concordant arguments from the molecular, bioacoustic and/or morphological data to accept five additional species in the genus Anodonthyla (A. emilei, A. jeanbai, A. pollicaris, A. theoi, A. vallani, besides the previously known $A$. boulengeri, A. hutchisoni, A. nigrigularis, A. montana, A. moramora, and $A$.rouxae). A summary of the major diagnostic differences between these species is given in Table 1. Taxonomic accounts and species descriptions are found in the Appendix and illustrated in Figs 7-17. The geographical distribution of all Anodonthyla species is summarized in Fig. 18. For three additional deep genealogical lineages our data are insufficient for a definitive taxonomic conclusion: Anodonthyla sp. aff. boulengeri 'Ranomafana' (including a strongly divergent population from Ambohitsara) is morphologically highly similar to $A$. boulengeri and A. pollicaris and the bioacoustic differences to A. pollicaris are minor. For this form, further work including independent (nuclear) molecular markers are needed to assess whether indeed it represents an independent evolutionarily lineage. In addition, two enigmatic individuals from Ranomafana clustered far from all other Anodonthyla and may represent two additional species, but no bioacoustic or morphological information is available for these individuals which therefore, following the terminology of Vieites et al. (2009), should be considered as unconfirmed candidate species.

\section{Discussion}

\section{Species diversity in Anodonthyla}

Numbers of amphibian species in Madagascar have recently experienced a steep increase (Köhler et al., 2005b; Vieites et al., 2009). This was caused by a number of factors. On one hand, a high intensity of field inventories in areas previously poorly surveyed for amphibians, but also at well-known sites. On the other hand, the stringent application of a combination of different data sets in taxonomic assessments, namely DNA barcoding, bioacoustics, and morphology. The application of DNA barcoding as a first step, with subsequent confirmation of candidate species by bioacoustics and/or morphology, has proven to be the most efficient approach, and Vieites et al. (2009) report on 126 undescribed but confirmed candidate species of amphibians from Madagascar. As already remarked by Wollenberg et al. (2008), cophylines are among the lineages with the highest proportion of undescribed species diversity, and also the proportion of unconfirmed candidate species (those defined by a high genetic divergence but unstudied for bioacoustics and morphology) is highest.

Our study in Anodonthyla shows that the candidate species of at least this cophyline genus are not just deep genealogical lineages, but also show clear bioacoustic and morphological differences upon detailed analysis and thus correspond to well-defined species, of which only a few qualify as true 'cryptic species'. For example, and besides the rather easily scored morphological differences mentioned in the species diagnoses, there are also more subtle but clear differences 
in morphometric variables defining most of the species (e.g. Fig. 6). It is also remarkable that the genetic divergences among species of Anodonthyla in general are very high. Low divergences are only observed among $A$. moramora and $A$. nigrigularis (2\% divergence in the 16S rRNA gene), and A. pollicaris and $A$. theoi $(3.5 \%)$. In contrast, all other pairwise comparisons yielded divergences of $7.4 \%$ or higher, up to $13.7 \%$ between $A$. vallani and one unconfirmed candidate species from Maharira (Ranomafana).

This latter unconfirmed candidate species merits some further discussion: in fact, it corresponds to a single sample (ZMA 20246, corresponding to field number ZCMV 204) of a possibly juvenile specimen collected in the leaf litter at Maharira, in syntopy with A. emilei. Because the corresponding voucher specimen was not available for our study, no further statements are currently possible, but considering the very high divergence of this sample to all other species of the genus $(9.7-13.7 \%)$, it is likely that a further undescribed species of Anodonthyla occurs at this site. Even more remarkable, a second isolated specimen collected during the same expedition at the same locality (no habitat or bioacoustic data; specimen ZCMV 257) shows, again, a deep divergence to all other species. Considering these two unconfirmed candidate species would bring the number of Anodonthyla in Ranomafana National Park up to five (in addition, $A$. sp. aff. boulengeri 'Ranomafana', A. emilei, and A. moramora).

Cophylines, in general are characterized by a relatively fast rate of mitochondrial evolution, at least compared to scaphiophrynines where substitutions appear to accumulate at a very slow pace in the mitochondrial DNA (Vences et al., 2002a). It is nevertheless unlikely that the deep divergences between most species of Anodonthyla are caused by a particularly fast mitochondrial substitution rate in this genus. Instead, we assume that most of these are in fact old species, and this hypothesis is supported by the fact that some well differentiated species in Anodonthyla show low divergences around or even below the threshold of 3\% 16S distance proposed by Fouquet $e t$ al. (2007) to delimit candidate species in frogs. One species for which we had samples from more than one population available for genetic analysis (A. boulengeri sensu stricto) in fact showed divergences of 1.1-1.6\% between populations which also had some important morphological differences. This indicates that our revision has certainly not completed the species inventory of Anodonthyla. Besides A. sp. aff. boulengeri 'Ranomafana', the two unconfirmed candidate species from Maharira, and possibly the deviant A. boulengeri population from Nosy Mangabe, we expect that further inventories, especially in the South East of Madagascar, will yield additional new species of this genus.

\section{Biogeography}

According to the previous classification, several species of Anodonthyla were relatively widespread. For instance, A. boulengeri was recorded from Marojejy to Andohahela along most the eastern escarpment of Madagascar (Blommers-Schlösser and Blanc, 1991), and A. nigrigularis from localities in the South East as well as from Ambohitantely at the western edge of the Northern Central East (Vallan, 2000).

Evidence has since progressively accumulated that these wide distributions are artificial and reflect poor taxonomic knowledge. Glaw and Vences (1992) described a new species, A. nigrigularis, from the extreme South East of Madagascar, invalidating records of $A$. boulengeri from this area. Vences et al. (2002b) found that the northernmost records from Marojejy in fact do not belong to the genus Anodonthyla. Fenolio et al. (2007) found what probably are the northernmost Anodonthyla populations and assigned them to a new species, A. hutchisoni, probably endemic to Masoala Peninsula. Finally, in the present paper, we demonstrate that the geographically disparate population of A. nigrigularis from Ambohitantely in fact represents a distinct species, $A$. vallani, and we partition A. boulengeri into three species: A. boulengeri sensu stricto, A. pollicaris, and A. sp. aff. boulengeri 'Ranomafana'.

As a consequence of this taxonomic progress, and if we disregard an unconfirmed record of A. montana from Andohahela (Blommers-Schlössser and Blanc, 1991), all species of Anodonthyla, except probably for A. boulengeri, are known from extremely small ranges only, and in part from only single sites (see maps in Fig. 18 in the Appendix). Because these animals have rather characteristic calls and are not particularly seasonal in their reproduction, we do not believe that these small ranges reflect undersampling but that, as a biological reality, Anodonthyla show a very high degree of microendemism. This conclusion is further supported by the genetic substructuring of A. boulengeri where the two populations from the offshore islands Nosy Mangabe and Nosy Boraha are differentiated genetically from each other and from 
the mainland populations (represented by Foulpointe). Such a microendemic pattern with very small extents of occurrence may be typical for cophylines in general (Wollenberg et al., 2008). This pattern also further reinforces our assumption that the species inventory of Anodonthyla is not yet completed, because it predicts additional new species in areas where intensive amphibian inventories followed by an integrative taxonomic approach are so far missing.

The distribution of Anodonthyla species diversity, and the phylogeny of the genus, further predicts that forested areas in the Southern Central East and South East of Madagascar most likely yield additional species of this genus. Glaw and Vences (2005) already stated that the center of species diversity and endemism of Anodonthyla is in southern Madagascar. This pattern was confirmed by the spatial analysis of Wollenberg et al. (2008), whereas several other cophyline lineages, such as Platypelis/Cophyla and Rhombophryne/Stumpffia, clearly have their centers of diversity and endemism in northern Madagascar. The new species descriptions herein further support this pattern, because four of the newly distinguished species $(A$. emilei, A. jeanbai, A. theoi, A. sp. aff. boulengeri 'Ranomafana') as well as the two unconfirmed candidate species from Maharira are from the South East or Southern Central East, while only two newly recognized species (A.pollicaris and A. vallani) occur in the Northern Central East.

Furthermore, none of the northern distributed species occupy a basal position in the molecular phylogeny: neither the lineage containing the two northernmost distributed species, A. hutchisoni and A. boulengeri, nor the northern-central distributed species $A$. pollicaris and A. vallani. In a more detailed view, A. pollicaris is phylogenetically nested in a clade containing three southern species (A. moramora, A. nigrigularis, and $A$.theoi), and the most parsimonious hypothesis is therefore that its ancestors dispersed northwards into its current northern range. In contrast, A. hutchisoni, $A$. boulengeri and $A$. vallani belong to a clade that contains only one southern species (A. sp. aff. boulengeri 'Ranomafana'), and this species is placed in a nested position, which supports that this lineage diversified at least partly in the Northern-Central-East. However, the most basal taxa of Anodonthyla (A. montana, A. rouxae, A. emilei, A. jeanbai) are southern endemics, all restricted to elevations of $1000 \mathrm{~m}$ above sea level or higher, supporting that the initial diversification of Anodonthyla took place in the mountains of the SouthEast or Southern Central East.

\section{Evolution of calls in Anodonthyla}

As typical for cophylines, the calls of most Anodonthy$l a$ are long regular series of tonal notes (see Appendix). Although note duration is variable among Anodonthyla, in general their notes are shorter than those of other cophylines, such as many representatives of Cophyla, Platypelis, and Stumpffia. This short note duration could be a synapomorphy of Anodonthyla. Of the four basal Anodonthyla, calls are only known for A. emilei, and these have a deviant general structure. To understand call evolution in this genus, obtaining call recordings of A. jeanbai, A. montana and A. roux$a e$ should thus be seen as a priority.

Not considering the deviant A. emilei, the calls of Anodonthyla vary along mainly three axes: note repetition rate (which depends on inter-note interval duration), note length, and spectral frequency. To the human ear, the most obvious is the temporal difference between calls with fast versus slow note repetition rates. Interestingly, the molecular phylogeny indicates recurrent shifts between low and high note repetition rates in calls, based mainly on three strongly supported sister groups: A. moramora with low repetition rate and A. nigrigularis with moderately low repetition rate; $A$. theoi with low repetition rate and $A$. pollicaris with high repetition rate; $A$. vallani with low repetition rate and $A$. sp. aff. boulengeri 'Ranomafana' with high repetition rate. The factors that influenced these recurrent shifts remain unexplored. Character displacement at first glance appears to be unlikely, because according to current knowledge none of these species pairs occur in sympatry. However, some support for the character displacement hypothesis comes from the fact that the species with the lowest note repetition rate $(A$. moramora, down to 0.6 notes/second) occurs in sympatry with the species with the highest rate (A. sp. aff. boulengeri 'Ranomafana', up to 3.1 notes/second).

\section{Conservation and IUCN red list assessment}

According to the Global Amphibian Assessment for Madagascar and its subsequent updates (Andreone $e t$ al., 2005a, 2008b), at present one species of Anodonthyla is classified as Endangered (A. rouxae), one species as Vulnerable (A. montana), one species as Least Concern ( $A$. boulengeri) and three species as Data Deficient (A. hutchisoni, A. moramora, A. nigrigularis). Considering the prevalent microendemic pattern of Anodonthyla and the fact that our intensive surveys over the past years did not yield a single range 
extension of any species but instead led to the discovery of numerous new species, a threatened category in our opinion is warranted for additional species.

No conservation-relevant new data have become available for Anodonthyla hutchisoni, A. montana, and $A$. rouxae, and we therefore propose no change in the red list status of these species.

Anodonthyla boulengeri, after the revision herein, occupies a much smaller area than previously thought. However, within its extent of occurrence the species is ubiquitous, also in cultivated landscapes, and it occurs in at least one protected area (Nosy Mangabe Special Reserve). We therefore continue considering this species as Least Concern.

Anodonthyla pollicaris is apparently distributed over a relatively small area, but the limits of its distribution are poorly assessed, as are its tolerance of habitat disturbance. We consider a status of Data Deficient for this species as adequate. A similar rationale applies to A. theoi; this species was found at a single site only, but nearby localities (e.g. Vevembe forest) are only poorly surveyed and the species may be more widespread. In addition, our observations are insufficient to assess whether $A$. theoi is a specialist of more or less intact rainforest or is also able to survive in heavily degraded and secondary forest, or even in cultivated landscape. We therefore propose to consider also this species as Data Deficient.

Anodonthyla nigrigularis has only been found at a limited number of sites (Manantantely, Pic St. Louis, Nahampoana, and low elevations of Andohahela National Park) in very close geographic proximity, whereas the Ambohitantely population assigned to this species has been found to represent a separate species (A. vallani). Low-elevation forests in south-eastern Madagascar are under heavy pressure, including those within Andohahela National Park (e.g. Ramanamanjato et al., 2002). On the other hand, we have observed A. nigrigularis also in secondary forest consisting of mainly eucalypt trees, indicating that this species has a reasonable tolerance to habitat degradation. This pattern is very similar to that of the mantellid frog Gephyromantis leucocephalus which also is endemic to South-Eastern lowlands but tolerates to some degree habitat degradation, and which Andreone et al. (2005a) included in the Near Threatened category. Based on the same rationale, we propose to also consider A. nigrigularis as Near Threatened.

Anodonthyla emilei is morphologically and bioacoustically distinct and yet has not been recorded from localities other than Ranomafana National Park where it is apparently restricted to higher elevations. This situation is identical to that of the mantellid frog $\mathrm{Ge}$ phyromantis runewsweeki, and following the rationale used for that species by Andreone et al. (2008b), we propose a status of Endangered for A. emilei because its $\mathrm{EOO}$ is less than $5000 \mathrm{~km}^{2}$, all individuals are in fewer than five locations, and there is probably a continuing decline in the extent and quality of much of its habitat. We apply the same rationale also to Anodonthyla moramora, and propose a status of Endangered to this species as well.

Anodonthyla vallani is restricted to Ambohitantely, an isolated protected area containing a series of forest fragments that are under heavy anthropogenic pressure. Similar to the conclusion drawn (Andreone et al., 2005a) for another microhylid endemic to this site, Stumpffia helenae, we propose a status of Critically Endangered for $A$. vallani.

With our proposal, one Anodonthyla is now categorized as Critically Endangered, three as Endangered, one as Vulnerable, one as Near Threatened, one as Least Concern, and three as Data Deficient. If the microendemic distribution pattern observed in Anodonthyla is confirmed by future studies, also for other cophyline lineages, we predict a similar increase in the number of threatened species also for these. However, it needs to be emphasized that this increase is not due to sharp declines but just to a better taxonomic resolution. Similar to the general situation in Malagasy amphibians (Andreone et al., 2008a), so far no catastrophic declines of Anodonthyla have been observed, all species are known from at least one legally protected area, and dense populations of all species have been observed in the wild in the period 2004-2009. The key to their conservation therefore continues to be an effective conservation of the remaining primary habitats, especially within the recently extended network of protected areas (Kremen et al., 2008).

\section{Acknowledgements}

We are grateful to Parfait Bora, Ignacio De la Riva, Rainer Dolch, Marta Puente, Liliane Raharivololoniaina, Roger-Daniel Randrianiaina, Jasmin E. Randrianirina, Theo Rajaofiarison, Emile Rajeriarison, Goran Safarek, Meike Teschke, and David R. Vieites for their help during fieldwork. Annemarie Ohler (MNHN) and Gunther Köhler (SMF) kindly loaned specimens for comparisons. This study has been carried out in the framework of various collaboration agreements with UADBA. The Malagasy authorities kindly granted research and export permits. The Institute for the Conservation of Tropical Environments (ICTE-MICET) and Valbio biological station provided crucial logistic support. Newly 
collected specimens examined for this study were obtained during expeditions supported by the Volkswagen Foundation and Deutscher Akademischer Austauschdienst to M.V. and F.G., and by Deutsche Forschungsgemeinschaft to M.V.

\section{References}

Andreone F, Cadle JE, Cox N, Glaw F, Nussbaum RA, Raxworthy CJ, Stuart SN, Vallan D, Vences M. 2005a. Species review of amphibian extinction risks in Madagascar: conclusions from the Global Amphibian Assessment. Conservation Biology 19: 1790-1802.

Andreone F, Vences M, Vieites DR, Glaw F, Meyer M. 2005b. Recurrent ecological adaptations revealed through a molecular analysis of the secretive cophyline frogs of Madagascar. Molecular Phylogenetics and Evolution 34: 315-322.

Andreone F, Aprea G, Odierna G, Vences M. 2006. A new narrow-mouthed frog of the genus Paradoxophyla (Microhylidae: Scaphiophryninae) from Masoala rainforest, northeastern Madagascar. Acta Herpetologica 1: 15-27.

Andreone F, Carpenter AI, Cox N, du Preez L, Freeman K, Furrer S, García G, Glaw F, Glos J, Knox D, Köhler J, Mendelson III JR, Mercurio V, Mittermeier RA, Moore RD, Rabibisoa NHC, Randriamahazo H, Randrianasolo H, Rasomampionona Raminosoa N, Ravoahangimalala Ramilijaona $\mathrm{O}$, Raxworthy CJ, Vallan D, Vences M, Vieites DR, Weldon C. 2008a. The challenge of conserving amphibian megadiversity in Madagascar. PLoS Biology 6: e118.

Andreone F, Cox N, Glaw F, Köhler J, Rabibisoa NHC, Randriamahazo H, Randrianasolo H, Raxworthy CJ, Stuart SN, Vallan D, Vences M. 2008b. Update of the Global Amphibian Assessment for Madagascar in light of new species discoveries, nomenclature changes, and new field information. Monografie del Museo Regionale di Scienze Naturali di Torino 45: 419-438.

Aprea G, Odierna G, Andreone F, Glaw F, Vences M. 2007. Karyological evolution and systematics of Malagasy microhylid frogs. Zoologischer Anzeiger 246: 23-41.

Avise JC, Ball RM. 1990. Principles of genealogical concordance in species concepts and biological taxonomy. Pp 45-67 in: Futuyma D, Antonovics J, eds., Surveys in Evolutionary Biology, vol. 7. Oxford University Press.

Blommers-Schlösser RMA. 1975. Observations on the larval development of some Malagasy frogs, with notes on their ecology and biology (Anura: Dyscophinae, Scaphiophryninae and Cophylinae). Beaufortia 24: 7-26.

Blommers-Schlösser RMA, Blanc CP. 1991. Amphibiens (première partie). Faune de Madagascar 75: 1-379.

Boettger O. 1913. Reptilien und Amphibien von Madagascar, den Inseln und dem Festland Ostafrikas. Pp. 269-375 in: Voeltzkow A, Reise in Ostafrika 3(4). Stuttgart: E. Schweitzerbart.

Boumans L, Vieites DR, Glaw F, Vences M. 2007. Geographical patterns of deep mitochondrial differentiation in widespread Malagasy reptiles. Molecular Phylogenetics and Evolution 45: 822-839.

Fenolio DB, Walvoord ME, Stout JF, Randrianirina JE, Andreone F. 2007. A new tree hole-breeding Anodonthyla (Chordata: Anura: Microhylidae: Cophylinae) from low-alti- tude rainforests of the Masoala Peninsula, northeastern Madagascar. Proceedings of the Biological Society of Washington 120: 86-98.

Fouquet A, Gilles A, Vences M, Marty C, Blanc M, Gemmell NJ. 2007. Underestimation of species richness in Neotropical frogs revealed by mtDNA analyses. PLOS ONE 2: e1109.

Glaw F, Vences M. 1992. A Fieldguide to the Amphibians and Reptiles of Madagascar. First edition. Köln: Vences und Glaw Verlag.

Glaw F, Vences M. 1994. A Fieldguide to the Amphibians and Reptiles of Madagascar. Second edition. Köln: Vences und Glaw Verlag.

Glaw F, Vences M. 1997. Anuran eye colouration: definitions, variation, taxonomic implications and possible functions. Pp. 125-138 in: Böhme W, Bischoff W, Ziegler T, eds., Herpetologia Bonnensis. Bonn: SEH Proceedings.

Glaw F, Vences M. 2005. A new arboreal microhylid frog of the genus Anodonthyla from south-eastern Madagascar (Amphibia, Microhylidae). Spixiana 28: 181-189.

Glaw F, Vences M. 2007. A Field Guide to the Amphibians and Reptiles of Madagascar. Third edition. Köln: Vences und Glaw Verlag.

Glos J, Glaw F, Vences M. 2005. A new species of Scaphiophryne from western Madagascar. Copeia 2005: 252-261.

Grosjean S, Glos J, Teschke M, Glaw F, Vences M. 2007. Comparative larval morphology of Madagascan toadlets of the genus Scaphiophryne: phylogenetic and taxonomic inferences. Zoological Journal of the Linnean Society 151: 555-576.

Guibé J. 1978. Les Batraciens de Madagascar. Bonner zoologische Monographien 11: 1-148.

Guindon S, Gascuel O. 2003. A simple, fast, and accurate algorithm to estimate large phylogenies by Maximum Likelihood. Systematic Biology 52: 696-704.

Hebert PDN, Cywinska A, Ball SL, DeWaard JR. 2003. Biological identifications through DNA barcodes. Proceedings of the Royal Society B 270: 313-321.

Köhler J, Scheelke K, Schick S, Veith M, Lötters S. 2005a. Contribution to the taxonomy of hyperoliid frogs (Amphibia: Anura: Hyperoliidae): advertisement calls of twelve species from East and Central Africa. African Zoology 40: 127-142.

Köhler J, Vieites DR, Bonett RM, Hita Garcia F, Glaw F, Steinke D, Vences M. 2005b. Boost in species discoveries in a highly endangered vertebrate group: new amphibians and global conservation. BioScience 55: 693-696.

Köhler F, Günther R. 2008. The radiation of microhylid frogs (Amphibia: Anura) on New Guinea: A mitochondrial phylogeny reveals parallel evolution of morphological and life history traits and disproves the current morphology-based classification. Molecular Phylogenetics and Evolution 47: 353-365.

Kremen C, Cameron A, Moilanen A, Phillips SJ, Thomas CD, Beentje H, Dransfield J, Fisher BL, Glaw F, Good TC, Harper GJ, Hijmans RJ, Lees DC, Louis Jr. E, Nussbaum RA, Raxworthy CJ, Razafimpahanana A, Schatz GE, Vences M, Vieites DR, Zjhra ML. 2008. Aligning conservation priorities across taxa in Madagascar with high-resolution planning tools. Science 320: 222-226.

Ramanamanjato JB, McIntyre PB, Nussbaum RA. 2002. Reptile, amphibian, and lemur diversity of the Malahelo forest, a biogeographical transition zone in southeastern Madagascar. Biodiversity and Conservation 11: 1791-1807. 
Ronquist F, Huelsenbeck JP. 2003. MRBAYES 3: Bayesian phylogenetic inference under mixed models. Bioinformatics 19: 1572-1574.

Stamatakis A, Hoover P, Rougemont J. 2008. A fast bootstrapping algorithm for the RAxML web-servers. Systematic Biology 57: 758-771.

Swofford DL. 2002. PAUP*. Phylogenetic Analysis Using Parsimony (* and other methods), Version 4. Sunderland, MA: Sinauer Associates.

Vallan D. 2000. Influence of forest fragmentation on amphibian diversity in the nature reserve of Ambohitantely, highland Madagascar. Biological Conservation 96: 31-43.

Van Bocxlaer I, Roelants K, Biju SD, Nagaraju J, Bossuyt F. 2006. Late Cretaceous vicariance in Gondwanan amphibians. PLOS ONE 1: e74.

Van der Meijden A, Vences M, Meyer A. 2004. Novel phylogenetic relationships of the enigmatic brevicipitine and scaphiophrynine toads as revealed by sequences from the nuclear Rag-1 gene. Proceedings of the Royal Society B (Suppl.) 271: S378-S381.

Van der Meijden A, Vences M, Hoegg S, Boistel R, Channing A, Meyer A. 2007. Nuclear gene phylogeny of narrow-mouthed toads (Family: Microhylidae) and a discussion of competing hypotheses concerning their biogeographical origins. Molecular Phylogenetics and Evolution 44: 1017-1030.

Vences M, Aprea G, Capriglione T, Andreone F, Odierna G. 2002a. Ancient tetraploidy and slow molecular evolution in
Scaphiophryne: ecological correlates of speciation mode in Malagasy relict amphibians. Chromosome Research 10: 127136.

Vences M, Glaw F, Andreone F. 2002b. Geographic distribution: Anodonthyla boulengeri. Herpetological Review 33: 61 .

Vences M, Vieites DR, Glaw F, Brinkmann H, Kosuch J, Veith M, Meyer A. 2003. Multiple overseas dispersal in amphibians. Proceedings of the Royal Society B 270: 2435-2442.

Vences M, Glaw F, Márquez R. 2006. The Calls of the Frogs of Madagascar. 3 Audio CDs and booklet. Barcelona: AlosaFonozoo.

Vieites DR, Wollenberg KC, Andreone F, Köhler J, Glaw F, Vences M. 2009. Vast underestimation of Madagascar's biodiversity evidenced by an integrative amphibian inventory. Proceedings of the National Academy of Science of the USA 106: 8267-8272.

Wollenberg KC, Vieites DR, van der Meijden A, Glaw F, Cannatella DC, Vences M. 2008. Patterns of endemism and species richness in Malagasy cophyline frogs support a key role of mountainous areas for speciation. Evolution 62: 18901907.

Received: 20 April 2009

Accepted: 7 November 2009

Published online: 21 January 2010

Editor: J.W. Arntzen 


\section{Appendix}

Taxonomic accounts and descriptions of new species

In the following we provide taxonomic notes on nominal species of Anodonthyla, and new species descriptions. Note that the diagnoses are organized sequentially, i.e., they do not provide distinctions from those new species described in subsequent sections. A full comparison of most diagnostic characters is given in Table 1.

Anodonthyla pollicaris (Boettger, 1913) bona species (Figs 7a-b)

Holotype. This species was described as Mantella pollicaris Boettger, 1913, based on the female holotype specimen SMF 4299 from Anevoka in eastern Madagascar, collected by Sikora in 1902.

Identity. As reported by Glaw and Vences (2005), the type locality of this species could not be located by Blommers-Schlösser and Blanc (1991), but is between Toamasina (Tamatave) and Tanaramé (Boettger, 1913: 273 ) and may correspond to a village ( $18^{\circ} 56^{\prime} \mathrm{S}$, $48^{\circ} 28^{\prime} \mathrm{E}, 936 \mathrm{~m}$ a.s.l.) with this name close to Andasibe. Although the holotype is a female, some of its morphological characters agree with specimens collected at Andasibe, such as the relatively large tympanum (Table 2), which however is not clearly visible and appears to be smaller in at least two other comparative specimens. Our phylogenetic data (Figs 1-2) provide clear evidence that the Andasibe specimens are to be considered as distinct species, different from all currently recognized Anodonthyla: Although they roughly agree in general morphology and note repetition rate with A. boulengeri, they are placed sister to a population from Manombo which has a much slower note repetition rate and several morphological differences (described as A. theoi below), and these two species further belong to a more inclusive clade with A. moramora and A. nigrigularis, also characterized by slow to very slow note repetition rates. There are no clear morphological characters that would allow to exclude conspecificity of the type of pollicaris

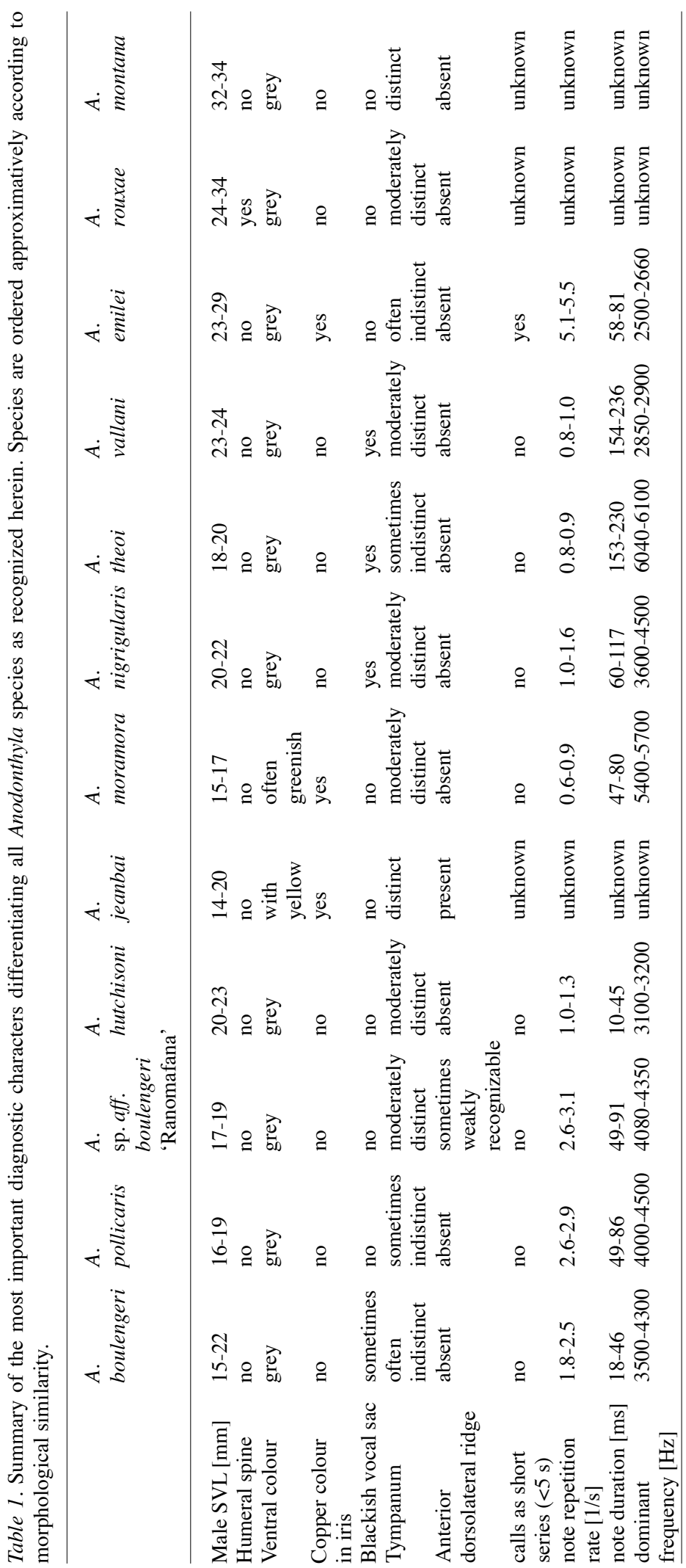




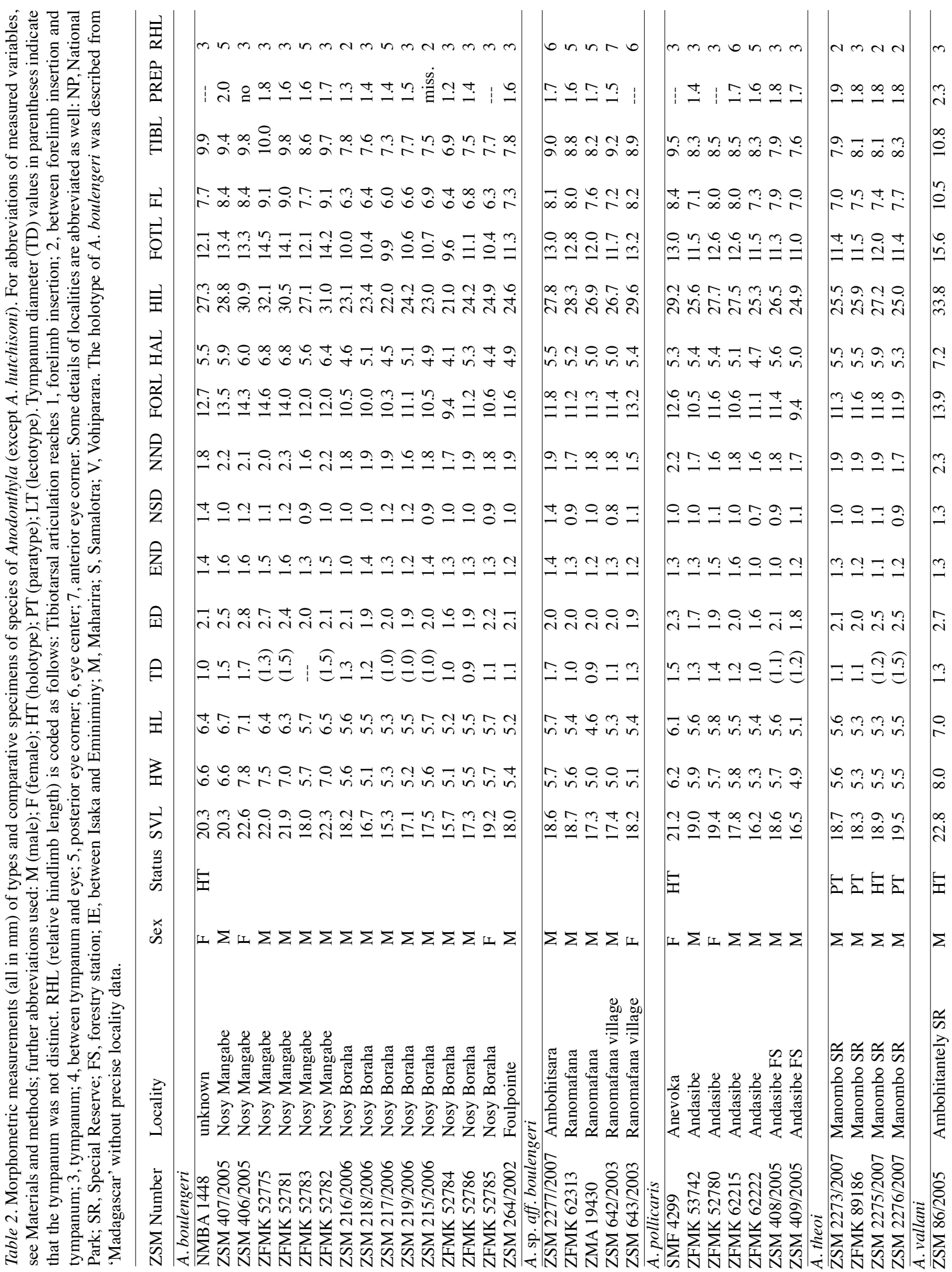




\begin{tabular}{|c|c|c|c|c|c|c|}
\hline & $m m-N m n$ & $n n n+m$ & in 0 in $0 \mathrm{~m}$ & $n m$ & - & $m \sim m m n$ \\
\hline & 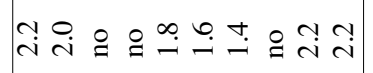 & 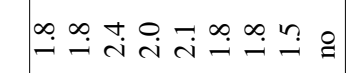 & 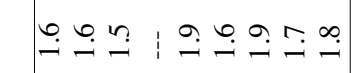 & ic & $i$ & 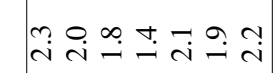 \\
\hline & 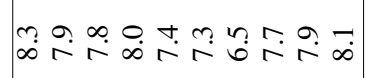 & 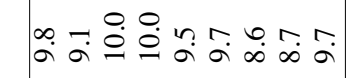 & 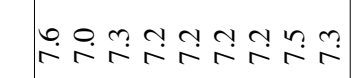 & $\mid \begin{array}{ll}n & 0 \\
= & 0 \\
= & 0\end{array}$ & $\stackrel{\nabla}{\sim}$ & 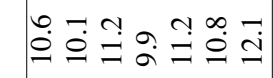 \\
\hline & 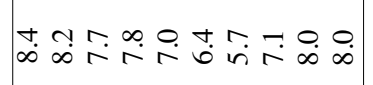 & 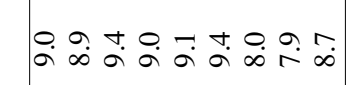 & 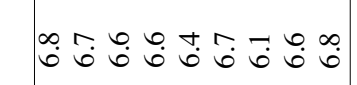 & $\ddot{m}$ & $m$ & 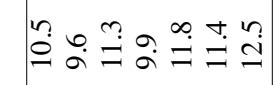 \\
\hline & 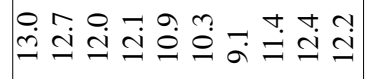 & $\stackrel{\circ}{\dot{\Xi}} \dot{m}$ & 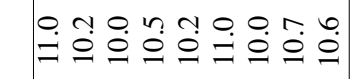 & ते & $\stackrel{m}{n}$ & تِ \\
\hline & 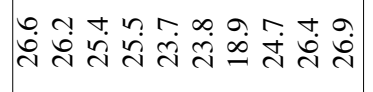 & 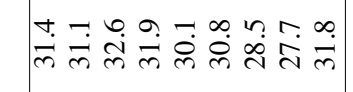 & تُ & 每 & $\stackrel{\bullet}{\vec{f}}$ & $=4$ \\
\hline & 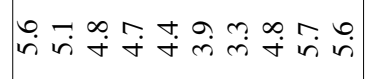 & గุ $0: 0 \%$ & 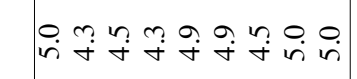 & กุ & 20 & 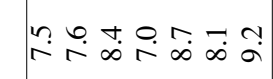 \\
\hline & 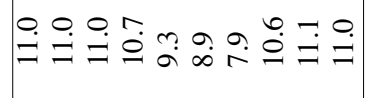 & $\ddot{m}:$ & 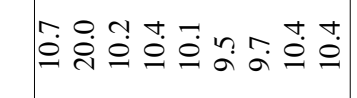 & 冓 & $\ddot{\partial}$ & $\because$ \\
\hline & 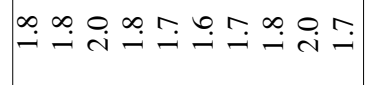 & บู & 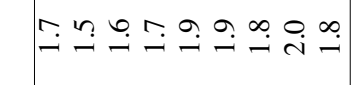 & $\begin{array}{ll}0 & \infty \\
\dot{r} & i\end{array}$ & $\dot{r}$. & $\theta+$ \\
\hline & 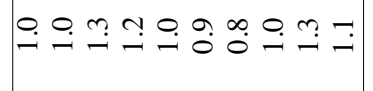 & 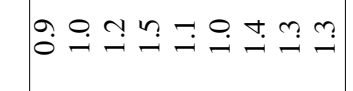 & 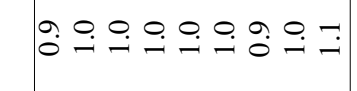 & 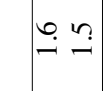 & $\left(\begin{array}{c}\mathrm{N} \\
\mathrm{i}\end{array} \mid\right.$ & 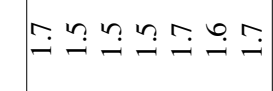 \\
\hline & 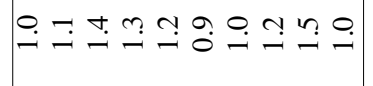 & m & 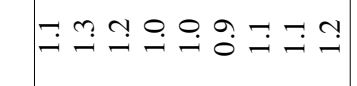 & ir & $\stackrel{\mathrm{N}}{\mathrm{N}}$ & 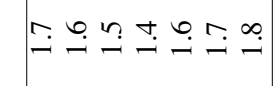 \\
\hline & 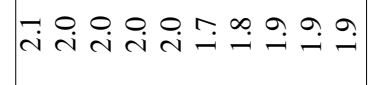 & 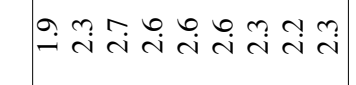 & 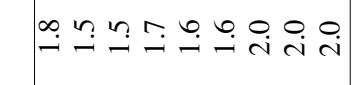 & $\ddot{\theta} \vec{m}$ & $\begin{array}{l}\infty \\
\infty\end{array}$ & ด $\infty \sim 0$ \\
\hline & 苛 & 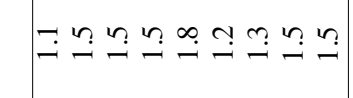 & 믐 & $\vec{i}$ & in & $\stackrel{n}{=} \stackrel{0}{=}$ \\
\hline & 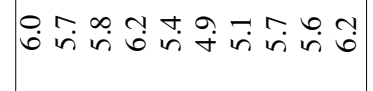 & 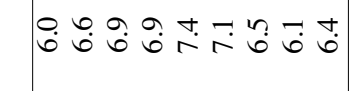 & tr. & 0. & $\because$ & 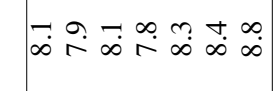 \\
\hline & 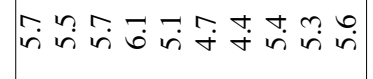 & 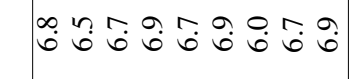 & inc & ă & $\stackrel{\sim}{=}$ & on in \\
\hline & 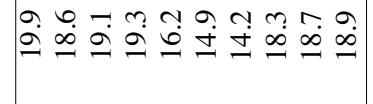 & $\vec{i}:$ & : & $m$ & ri. & 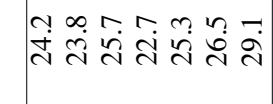 \\
\hline & 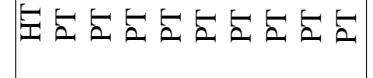 & E & 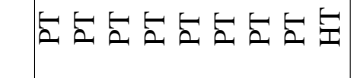 & & $\Xi$ & 氙占占 \\
\hline & $\Sigma \Sigma$ & $\Sigma \Sigma \Sigma \Sigma \Sigma \Sigma \Sigma$ & $\Sigma \Sigma$ & $\sum$ & $L_{1}$ & $\Sigma$ \\
\hline & 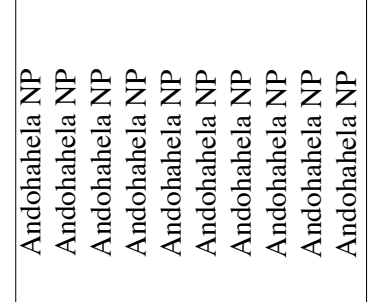 & 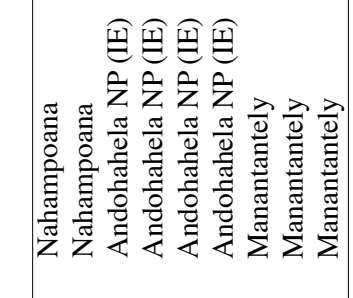 & 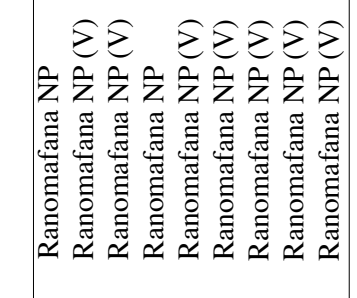 & 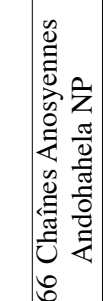 & 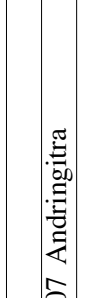 & 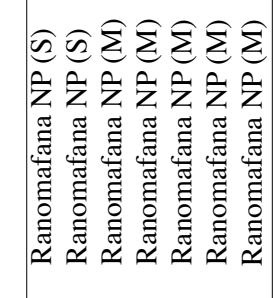 \\
\hline & 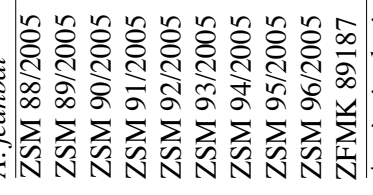 & 至 & 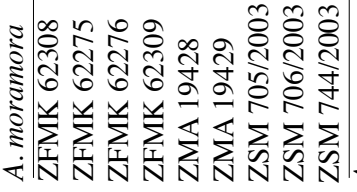 & 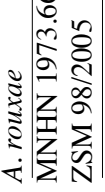 & 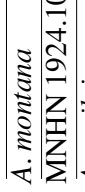 & \\
\hline
\end{tabular}




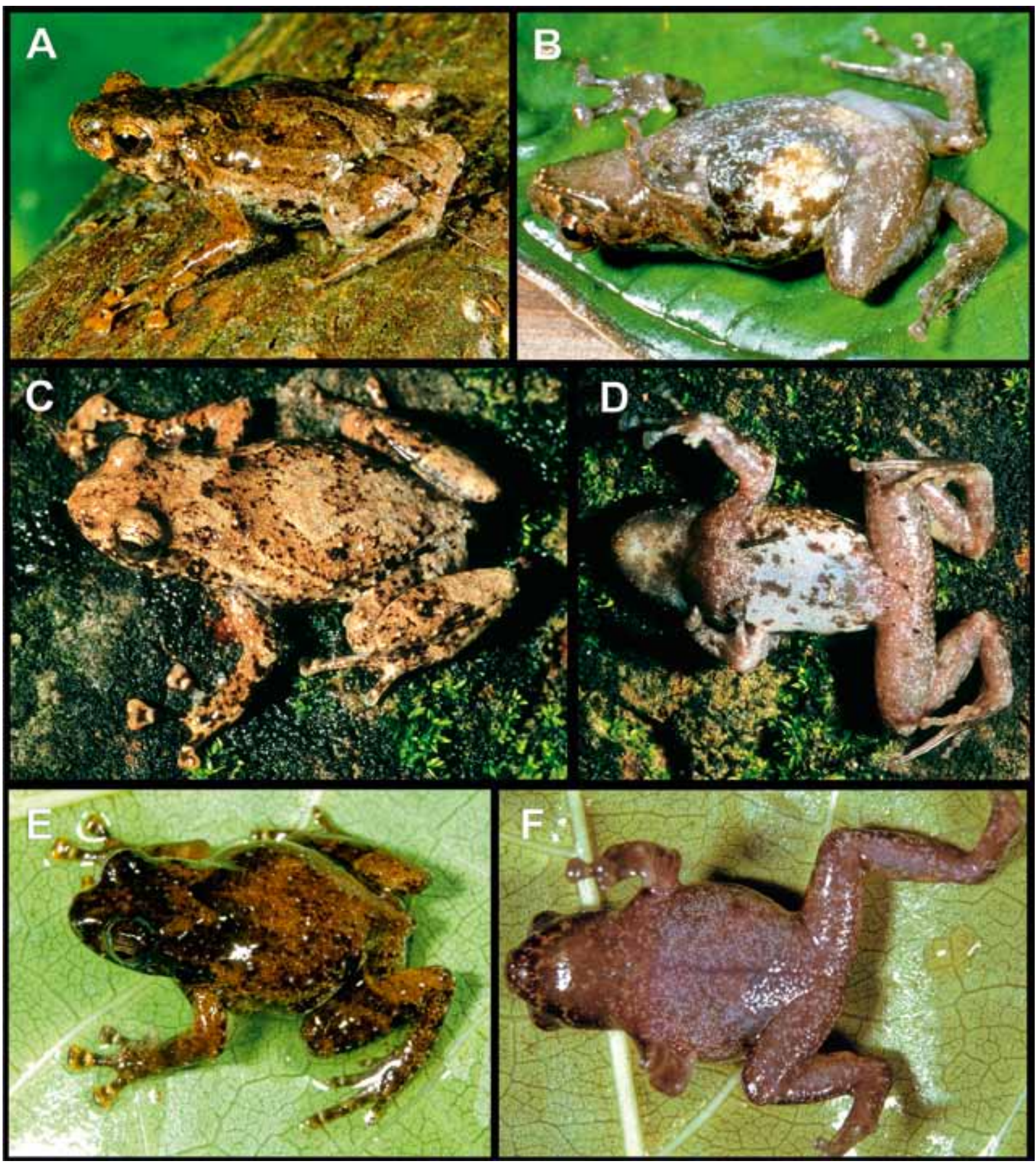

Fig. 7a-f. Specimens in life, in dorsolateral and ventral view, of Anodonthyla pollicaris from Andasibe (A-B); A. boulengeri from Nosy Mangabe (C-D); and Nosy Boraha (E-F) (all males).

with this distinct species from the Andasibe region, and as a measure of taxonomic parsimony we therefore here resurrect the name Anodonthyla pollicaris for this species.
Diagnosis. A moderately small arboreal frog with a fast repetition rate of advertisement calls, assigned to Anodonthyla on the basis of the presence of a distinct prepollex in males. Distinguished from all other 
Anodonthyla by a significant genetic differentiation. Further distinguished from A. montana and $A$. rouxae by a clearly smaller body size, and from A. moramora by a larger body size (Tables 1 and 2). Further distinguished from A. moramora, A. hutchisoni, and A. nigrigularis by a distinctly faster repetition rate of advertisement calls. The species is most similar to A. boulengeri, and reliable morphological characters to distinguish these two species are unknown. However, the two species can be distinguished by subtle differences in advertisement calls, namely a faster note repetition rate and longer note duration in A. pollicaris (see Table 3 and below).

Redescription. Based on ZSM 408/2005 (ZCMV 2207), an adult male from Andasibe. Specimen in good state of preservation (left arm removed as tissue sample for molecular analysis). SVL $19.9 \mathrm{~mm}$ (for other measurements see Table 2). Body moderately slender; head very slightly wider than long, not wider than body; snout slightly pointed in dorsal view, rounded in lateral views; nostrils directed laterally, slightly protuberant, of almost same distance to tip of snout and to eye; canthus rostralis indistinct, concave; loreal region straight; tympanum moderately distinct, rounded, its diameter $52 \%$ of eye diameter; supratympanic fold recognizable; tongue ovoid, posteriorly broader than anteriorly, free and not notched or forked; maxillary teeth very poorly recognizable; vomerine teeth absent; choanae rounded. Arms moderately thickened; subarticular tubercles well recognizable at the base of fingers; outer metacarpal tubercle distinct; prepollex distinct, extending from the area generally occupied by the inner metacarpal tubercle to a point at the base of digital pad of first finger; tips of first finger and prepollex not diverging; fingers without webbing; relative length of fingers $1<2<4<3$, inner finger rudimentary with rounded disk, disks of fingers 2-4 distinctly enlarged, of triangular shape; keratinized nuptial pads absent, but a distinctly thickened less pigmented area on inner side of arm. Hindlimbs slender; tibiotarsal articulation reaching tympanum when hindlimb adpressed along body; TL $42 \%$ of SVL; lateral metatarsalia strongly connected; metatarsal tubercles poorly recognizable; no webbing between toes; relative length of toes $1<2<5<3<4$; third toe distinctly longer than fifth. Skin on dorsum and ventral surface smooth.
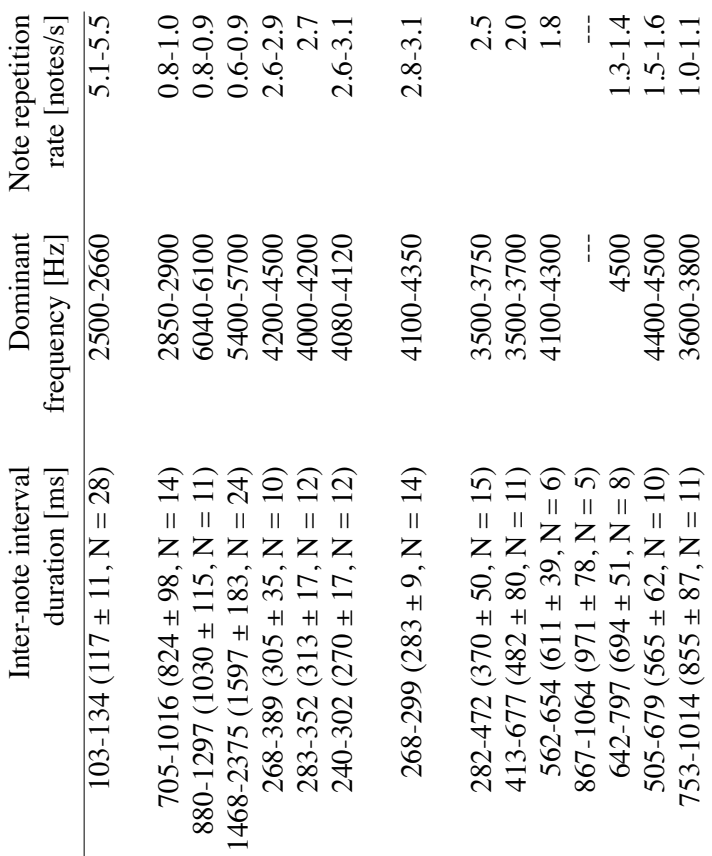

กิิㅡำ

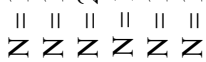
ขึ $+1+1+1+1+1$ $\stackrel{\infty}{=}:$ iv

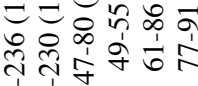
䓀

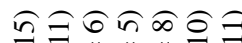
II II II II II Z Z Z Z Z Z Z 0ं ले

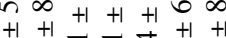

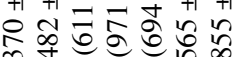

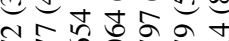

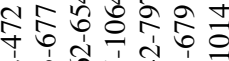

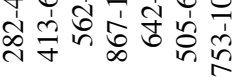

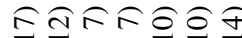
\| \|" $\|$ \| \| Z Z Z Z Z Z

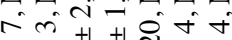
$+1+1000+1$

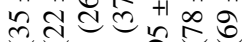

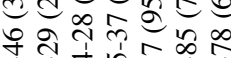

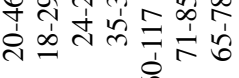

$$
\begin{aligned}
& \text { | }
\end{aligned}
$$

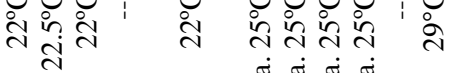

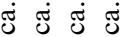

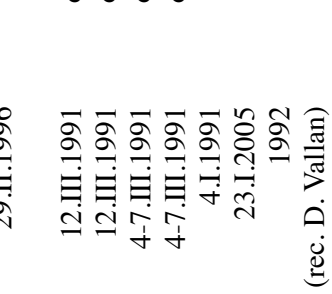

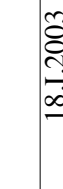

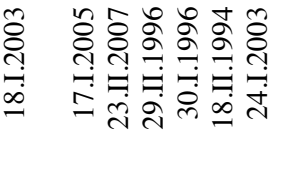
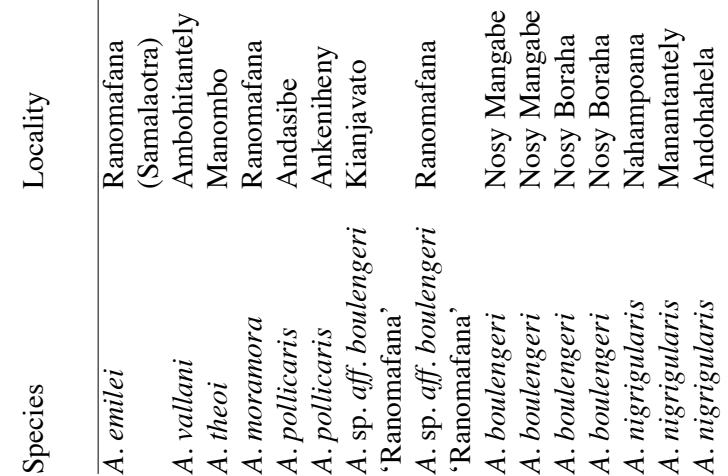
Colour. After four years in preservative, dorsum and head dark brown marbled with several distinct beige markings: a thin bar between the eyes, a Wshaped marking on the neck, a broad, irregular and slightly triangular crossband at middorsum, and an oval spot on posterior dorsum. Flanks marbled brown and beige. Tympanic region light, bordered by a dark supratympanic region. Forelimbs without distinct dark crossband, hindlimbs with distinct dark crossbands, bordered by beige. Cloacal region blackish. Throat brown, chest, belly and ventral parts of limbs dirty yellowish to grey with scattered brown pigment. Thickened ventral sides of arms less intensely pigmented.

Advertisement call. Based on data in Glaw and Vences (2005) and provided here as comparative oscillograms (Fig. 3) and in Table 3, the calls of A. pollicaris are characterized by a relatively fast note repetition rate of 2.6-2.9 notes per second and a note length of 49-86 ms. Note repetition rate is thus slightly higher than in A. boulengeri (1.8-2.5 notes/second) although the recordings of $A$. pollicaris calls were obtained at lower temperatures (Table 3 ).

Natural history. Calling males of A. pollicaris were found at night in mid-altitude rainforest, 1-3 $\mathrm{m}$ high on tree trunks and in a water-filled hole in a tree fern (Glaw and Vences, 1994; further own observations).

Distribution. Based on genetic and bioacoustic data, this species is known from (1) the type locality Anevoka, (2) Andasibe, including Analamazoatra/ Mantadia National Park, and (3) Ambavaniasy. Based on bioacoustic data only (Fig. 3), the species is also known from Ankeniheny.

\section{Anodonthyla boulengeri Müller, 1892 (Figs 7c-f)}

Holotype. This species was described based on a female holotype (NMBA 1448) originating from Madagascar, without further locality information.

Identity. Historically, especially populations from lowlands in the Malagasy east coast were assigned to this species (Blommers-Schlösser, 1975; BlommersSchlösser and Blanc, 1991) although also records from Andasibe, Ranomafana and Andohahela were published which according to our data refer to populations that are not conspecific with the Northern Central East coast populations. As the taxonomically most parsimonious solution, we here propose to continue considering populations from the Northern Central East coast (here represented by Nosy Mangabe, Foulpointe, and Nosy Boraha) as A. boulengeri. This is also in general agreement with morphological data. Although the holotype of A. boulengeri is a female and most other specimens studied by us are males, in general Anodonthyla appear to show only a limited sexual size dimorphism, if any. The SVL of the A. boulengeri holotype (20.3 $\mathrm{mm}$ ), its rather well visible but small tympanum, and other morphometric characters are in agreement with, for example, the studied male specimen from Foulpointe (ZSM 264/2002). For diagnostic characters of A. boulengeri, see Table 1 .

Genetic differentiation. The three populations studied herein show a considerable genetic divergence which amounts to $1.1 \%$ uncorrected $16 \mathrm{~S}$ divergence between Foulpointe and Nosy Mangabe and 1.6\% between Nosy Boraha (sequenced specimen: ZSM 219/2006; not included in tree because a different nonoverlapping fragment of the $16 \mathrm{~S}$ rRNA gene is available for this individual) and the two other populations. Two individuals sequenced from Nosy Mangabe (ZSM 407/2005 and UADBA-ZCMV 2141) had identical sequences.

Advertisement call. Based on data given in Glaw and Vences (2005) and shown here in Table 3 and Fig. 3 , the two populations of $A$. boulengeri studied for their advertisement calls (Nosy Boraha and Nosy Mangabe) have very similar call parameters. They are characterized by high note repetition rates of 1.8-2.5 per second, and very short note duration of $18-46 \mathrm{~ms}$. Calls of A. hutchisoni, which occurs geographically close to the Nosy Mangabe population, differ by a lower note repetition rate of 1.0-1.3 notes per second. In contrast, populations from the Andasibe and Ranomafana regions, which we here consider as two species distinct from $A$. boulengeri, differ by longer notes of 49-86 ms duration.

Natural history. Calling males of A. boulengeri are found at night at perch heights of 1-3 $\mathrm{m}$ on tree trunks in rainforest (Nosy Mangabe) but also commonly in degraded forest, and in secondary vegetation with trees, in cultivated landscapes (Foulpointe and Nosy Boraha). Reproduction takes place in tree holes, and in leaf axils of Ravenala and Typhonodorum (observations from Foulpointe, Nosy Mangabe: BlommersSchlösser 1975; Glaw and Vences 1994).

Distribution. Based on molecular and bioacoustic data available, three populations can be assigned to $A$. boulengeri: Foulpointe, Nosy Mangabe, and Nosy Boraha. It can be assumed that other populations reported by Blommers-Schlösser and Blanc (1991) from the same coastal area belong to this species as well: Tampolo, Fenoarivo, Ivoloina, and Vokaraharo. 


\section{Anodonthyla sp. aff. boulengeri 'Ranomafana' (Fig. 8)}

Identity. As reported by Glaw and Vences (2005), in Ranomafana, forests at higher elevations (roughly above $900 \mathrm{~m}$ ) are occupied mainly by Anodonthyla moramora, whereas at lower elevations, populations of a different Anodonthyla occur that are morphologically and bioacoustically similar to A. boulengeri (and A. pollicaris). The molecular tree shows, however, that this form from Ranomafana is genetically highly distinct from A. boulengeri and A. pollicaris, and is sister to a morphologically and bioacoustically divergent population from Ambohitantely (described below as A. vallani). In addition, the calls from the Ranomafana region show some subtle differences to A. boulengeri. It therefore seems to be clear that the populations from the Ranomafana region previously assigned to A. boulengeri in fact belong to a distinct, undescribed species. We here refrain from describing this new species because the data available to us are too fragmentary: call recordings and DNA sequences partly do not refer to the same individuals and sites, and many of the recorded and sequenced individuals were not available for morphological study. In general, a future detailed revision of the Anodonthyla populations characterized by fast note repetition rates is necessary, using a combined genetic and bioacoustic assessment of populations from a more comprehensive geographic coverage, and including contact zones between genetically divergent forms still included in A. boulengeri (e.g. Nosy Boraha vs. Nosy Mangabe and Foulpointe; see above). We thus here provide only preliminary data on the populations from the Ranomafana region which we consider as confirmed candidate species following the terminology of Vieites et al. (2009).

Diagnosis. A moderately small arboreal frog with a fast repetition rate of advertisement calls, assigned to Anodonthyla on the basis of the presence of a distinct prepollex in males. Distinguished from all other Anodonthyla by a significant genetic differentiation. Further distinguished from A. montana and A. rouxae by a clearly smaller body size, and from the sympatric $A$. moramora by a larger body size (Table 2). Further distinguished from A. moramora, A. hutchisoni, and A. nigrigularis by a distinctly faster repetition rate of advertisement calls. The species is most similar to $A$. boulengeri and A. pollicaris and reliable morphological characters to distinguish it from these two species are unknown. However, A. sp. aff. boulengeri 'Ranomafana' can be distinguished from A. boulengeri by a faster note repetition rate and longer note dura- tion, while its advertisement calls are very similar to those of A. pollicaris (see Table 1 and 3, and call descriptions in the sections below).

Advertisement call. Call recordings are available from Ranomafana (Glaw and Vences, 2005) and from near Kianjavato (this paper, Figs 3 and 9), and the calls from the two localities are concordant in their temporal and spectral characters (Table 3 ). They have a high note repetition rate of 2.6-3.1 notes per second and a note duration of 49-91 ms. Note repetition rate is thus higher than in A. boulengeri (1.8-2.5 notes/second) although the recordings of calls of $A$. sp. aff. boulengeri 'Ranomafana' were obtained at lower temperatures (Table 3).

Natural history. Calling males of this species were observed at night in rainforest, but also in cultivated landscape far from forest (gardens of Ranomafana village), on tree trunks at perch heights of 1.5-3 m.

Distribution. The species is probably widespread in low elevations in the Southern Central East of Madagascar. Bioacoustically identified specimens are from (1) Ranomafana National Park including Ambatolahy and Talatakely and (2) near Kianjavato, genetic data are available from a specimen from (3) Ranomafana village (UADBA-ZCMV 13), from field observations, a DNA sequence and a photograph from (4) Mahakajy private reserve, and (5) from genetically divergent specimens from Ambohitsara (Fig. 8C).

Anodonthyla emilei sp. nov. (Fig. 10)

Holotype. ZSM 673/2003 (field number FG/MV 20020267), adult male, collected at Samalaotra (21 ${ }^{\circ} 14.113^{\prime} \mathrm{S}, 4^{\circ} 23.767^{\prime} \mathrm{E}$, ca. $1000 \mathrm{~m}$ a.s.1.), Ranomafana National Park, Fianarantsoa Province, Southern Central East of Madagascar, on 18 January 2003 by F. Glaw, M. Puente, L. Raharivololoniaina, M. Thomas and D. R. Vieites.

Paratypes. ZSM 674/2003 (field number FG/MV 2002-0268), adult male, same data as holotype; ZSM 366-369/2004 (field numbers ZCMV 214-216, 300) and ZFMK 89185 (=ZSM 365/2004, field number ZCMV 213), five adult males, collected at Ranomafana National Park (Maharira, base camp), $21^{\circ} 19.547^{\prime} \mathrm{S}$, $47^{\circ} 24.147^{\prime} \mathrm{E}$, about $900-1000 \mathrm{~m}$ a.s.l., Fianarantsoa Province, Southern Central East of Madagascar, on 24 January 2004 by M. Vences, I. De la Riva, E. Rajeriarison and T. Rajofiarison.

Justification. This species occupies a largely isolated position in the phylogenetic tree, with very high genetic divergences to all other Anodonthyla (16S pairwise distances 8.3-13.4\%), and furthermore has 


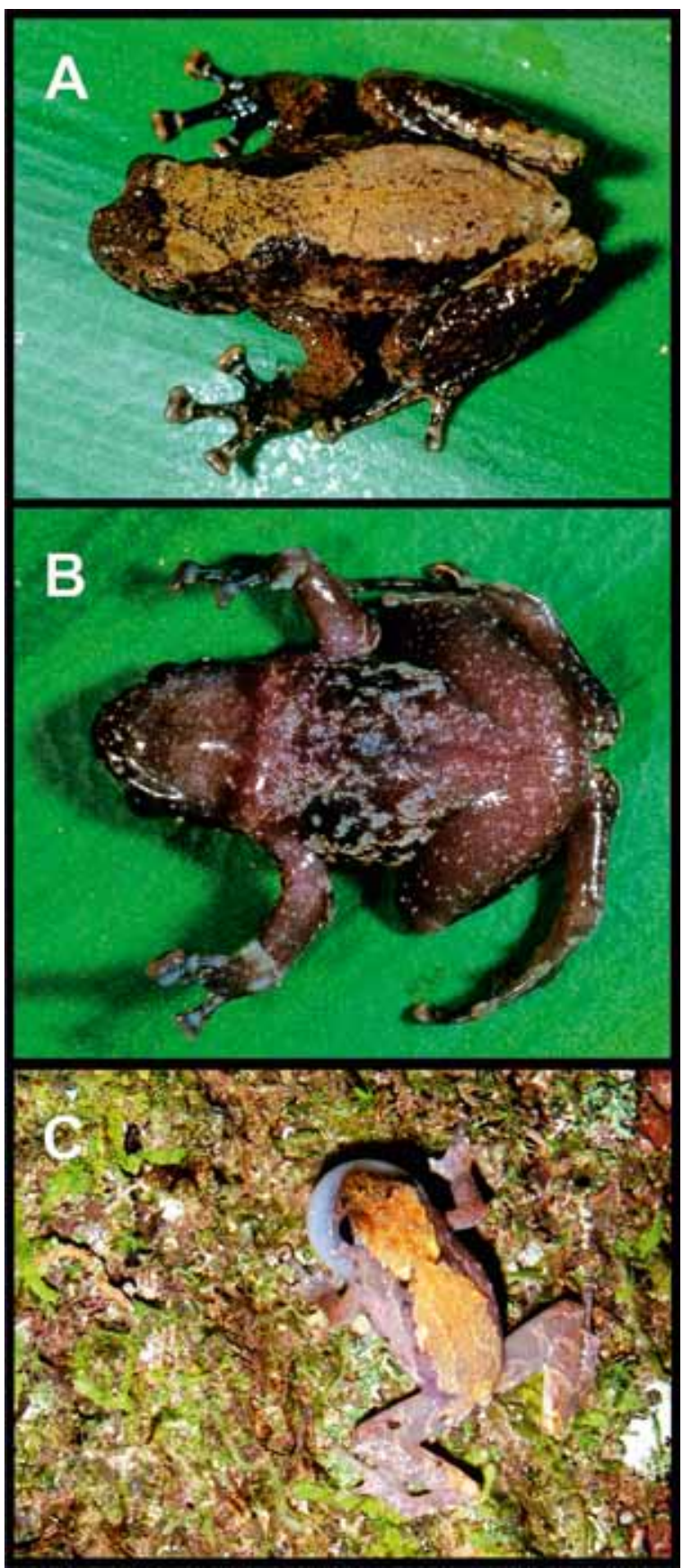

Fig. 8a-c. Male specimen of Anodonthyla sp. aff. boulengeri 'Ranomafana' in life (ZSM 642/2003) from Ranomafana in dorsolateral and ventral view (A-B); and a further specimen from Mahakajy private reserve (near Ranomafana) photographed at night calling $(\mathrm{C}$; not collected). Although both specimens show a large light patch on the dorsum, this colour pattern is not typical for all individuals of this species.

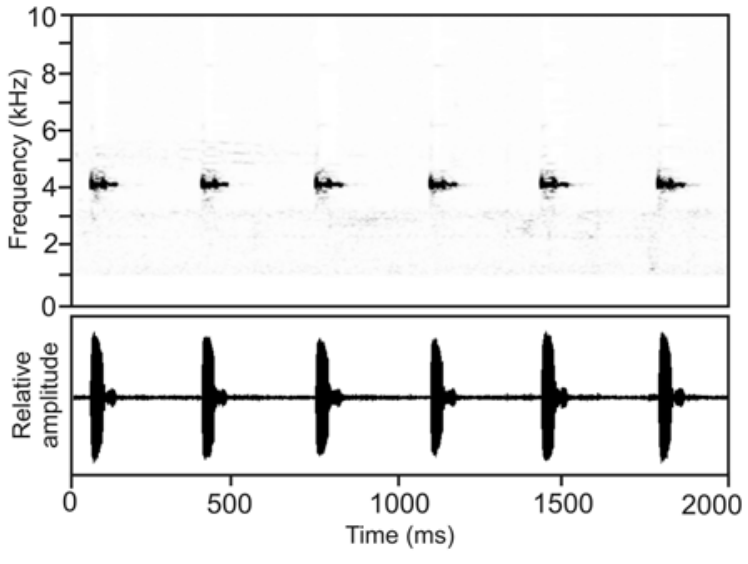

Fig. 9. Spectrogram and waveform of a part of a call series of Anodonthyla sp. aff. boulengeri 'Ranomafana', recorded near Kianjavato on 24 January 2003.

the most divergent call of all Anodonthyla. Its species status is therefore beyond question.

Diagnosis. A medium-sized species of Anodonthyla assigned to the genus on the basis of the presence of a distinct prepollex in males. Distinguished from all other Anodonthyla by a significant genetic differentiation, and from all species (except $A$. montana and $A$. rouxae where the calls are unknown) by advertisement calls which are a short series of fastly repeated short notes (vs. slower repetition of calls, with series that can last for at least several minutes). A. emilei is further distinguished from $A$. montana by smaller size (male SVL 24-27 vs. 32-34 mm), a less strongly developed supratympanic fold, and less distinct tympanum; from A. rouxae by the absence of distinct humeral spines in males (vs. presence) and generally by the presence of some coarse tubercles on body (vs. smooth skin); and from A. rouxae and A. montana by the presence of at least a slight shade of copper in the iris colouration (vs. absence). A. emile $i$ is distinguished from A. boulengeri, $A$. sp. aff. boulengeri 'Ranomafana', $A$. hutchisoni, A. moramora, A. nigrigularis, and A. pollicaris by a larger body size (male SVL $24-27$ vs. 15$23 \mathrm{~mm}$ ). Many specimens of A. emilei show a strongly contrasted colouration and the presence of orange dorsal patches of different size, not known thus far from other species in this genus. In males of A. emilei, the forelimbs are furthermore less distinctly enlarged than in various other species of Anodonthyla, and the tympanum is usually less distinct.

Description of holotype. Specimen in excellent state of preservation (fourth finger of right hand removed as tissue sample for molecular analysis). SVL 
$24.2 \mathrm{~mm}$ (for other measurements see Table 2). Body moderately slender; head wider than long, not wider than body; snout rounded in dorsal and lateral views; nostrils directed laterally, slightly protuberant, in same distance to tip of snout and to eye; canthus rostralis moderately distinct, concave; loreal region straight; tympanum indistinct, rounded, its diameter $59 \%$ of eye diameter; supratympanic fold indistinct; tongue ovoid, posteriorly broader than anteriorly, free and not notched or forked; small maxillary teeth present; vomerine teeth absent; choanae rounded. Arms slender, only slightly thickened; subarticular tubercles only recognizable at the base of fingers; outer metacarpal tubercle indistinct; prepollex medium-sized and distinct, extending from the area generally occupied by the inner metacarpal tubercle to a point below digital pad of first finger; tips of first finger and prepollex almost parallel; fingers without webbing; relative length of fingers $1<2=4<3$, inner finger rudimentary, with rounded, slightly enlarged disk, disks of fingers 2-4 distinctly enlarged, of triangular shape; nuptial pads absent. Hindlimbs slender; tibiotarsal articulation reaching the tympanum when hindlimb adpressed along body; TL $44 \%$ of SVL; lateral metatarsalia strongly connected; metatarsal tubercles poorly recognizable; no webbing between toes; relative length of toes $1<2<5<3<4$; third toe slightly longer than fifth. Skin on dorsum and ventral surface smooth.

Colour. After six years in preservative, dorsum dark grey-brown with a large, well-delimited symmetrical beige marking on each flank from the tympanic region to the groin, an inverse, brown $\mathrm{V}$-shaped marking on posterior dorsum and small light brown, darkly bordered tubercle-like spots scattered on the back. Surface of head dark brown except a narrow light brown stripe between the eyes. Tympanic region dark brown bordered by a light line. Each forelimb with one distinct dark crossband, hindlimbs with several dark crossbands. The ventral side is uniformly cream. In life, the general pattern of markings and flecks is almost identical to that in preservative. Dorsum brown with cream markings and scattered irregular orange spots, well-delimited large symmetrical bright orange marking on each flank, irregular in outline, from the tympanic region to the groin. Irregular orange fleck on each heel. Dorsal surfaces of fingers and toes with a reddish tint and irregular small brown flecking. Surface of head pale brown, narrow cream stripe between the eyes. Tympanic region dark brown bordered by a cream line. Each forelimb with one distinct and one indistinct brown crossband, hindlimbs with several brown crossbands. Cloacal region scattered with small whitish spots. Ventral surfaces fleshy white, with a bluish-violet tint on belly, throat pale brown. Iris brown with a copper tint and irregular black flecking and reticulation (Fig. 10A-B).

Variation. In comparison to the holotype, orange dorsal colour is less extensively distributed in the paratypes. In ZSM 674/2003 and 368/2004 the large irregular flecks are lacking, instead two smaller orange flecks are present dorsally in the scapular region and at level of the sacral vertebra, respectively (Fig. 10C). Another specimen (Fig. 10D) completely lacks the orange colour. The outline of darker markings on dorsum might be more or less distinctly recognizable. There seems to be also some variation concerning the dorsal skin texture in living individuals, with some individuals having almost smooth skin, others having scattered tubercles, and again others showing a finely tuberculate skin. Measurements are provided in Table 2. Several specimens of A. emilei show different degrees of separation of the prepollex and the first finger: for instance, in ZFMK 89185 (=ZSM 365/2004) prepollex and first finger are partly separated, whereas in ZSM $369 / 2004$, a full separation is observed on left hand.

Etymology. We are pleased to dedicate this new species to Emile Rajeriarison, nature guide at Ranomafana National Park and one of the most knowledgeable experts of diversity and natural history of Madagascar's rainforest fauna. Emile was present during the discovery of several specimens of this new Anodonthyla and collected part of the type series himself.

Advertisement call. Vocalization was recorded on 18 January 2003 at $21: 00 \mathrm{~h}$ (air temperature $20.6^{\circ} \mathrm{C}$ ) at Ranomafana National Park (Vences et al., 2006, CD 3, track 74). The advertisement call (Figs 4,11) consists of short unpulsed, melodious notes of $58-81 \mathrm{~ms}$ duration, repeated in fast succession and grouped to series containing 13-14 notes $(\mathrm{N}=3)$. Duration of these series is $2300-2580 \mathrm{~ms}(\mathrm{~N}=3)$, resulting in a repetition rate of 5.1-5.5 notes/second within series. Intervals between these call series are irregular and may last 14.2 seconds $(\mathrm{N}=1)$. Dominant frequency of notes is 2500 $2660 \mathrm{~Hz}$, additional call energy is present in a narrow frequency band at $7620-7990 \mathrm{~Hz}$. There is some frequency modulation present within note series, with a slight increase in frequency from the initial to the terminal notes of a series. Although barely recognizable in our analysis, frequency modulation seems also to be present in each note, with an initial upward sweep and a short terminal drop. Compared to known calls of 


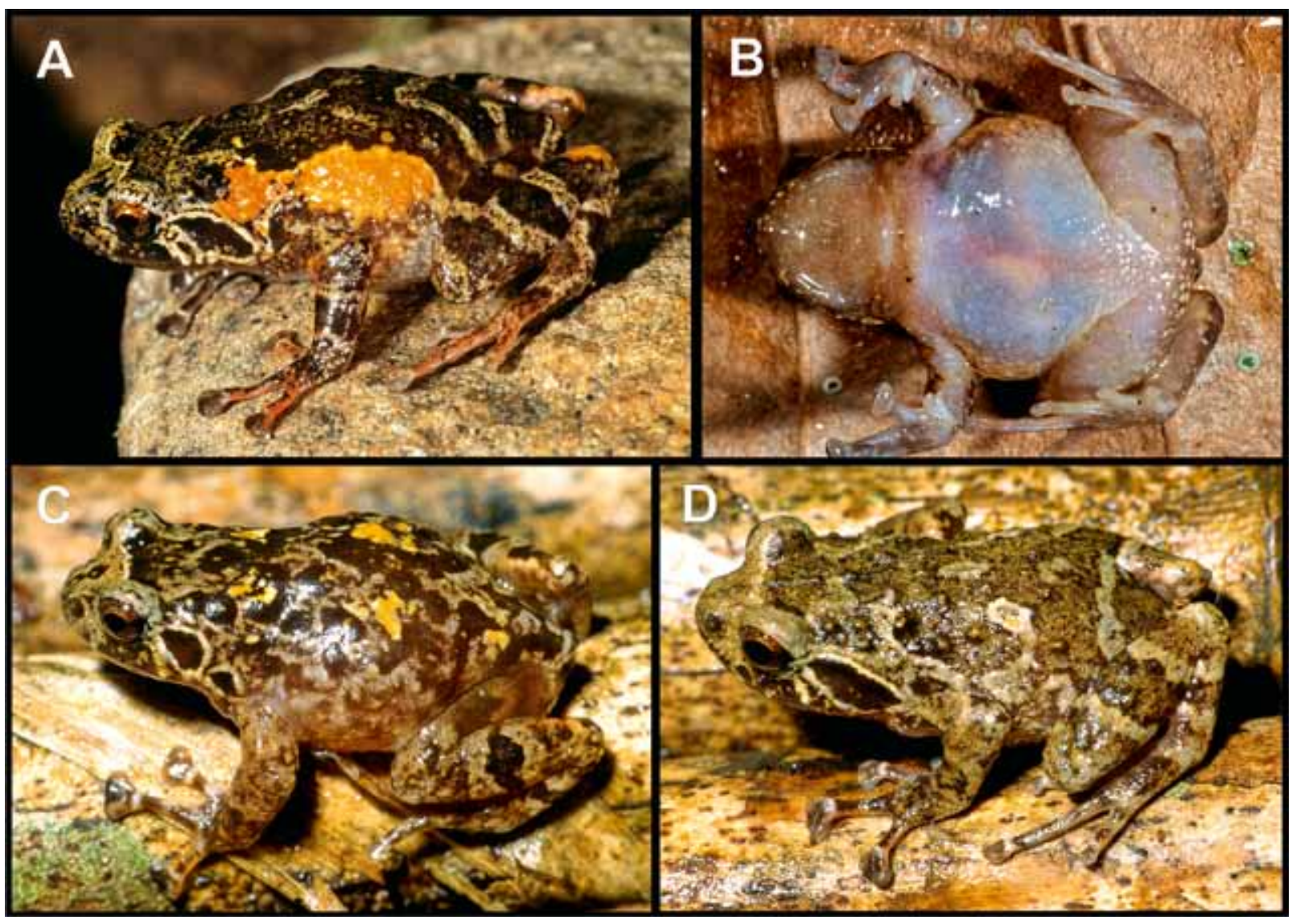

Fig. 10a-d. Specimens of Anodonthyla emilei in life (all males). (A-B) Holotype specimen ZSM 673/2003 from Samalaotra (Ranomafana National Park) in dorsolateral and ventral views; (C-D) paratypes ZSM 368/2004 and 366/2004 from Maharira (Ranomafana National Park) in dorsolateral view.

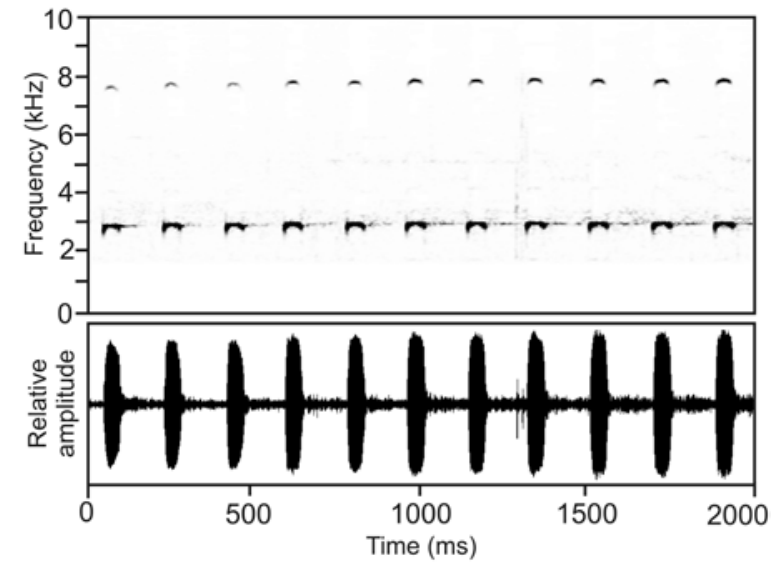

Fig. 11. Spectrogram and waveform of a part of a call series of the holotype of Anodonthyla emilei, recorded at Samalaotra (Ranomafana National Park) on 18 January 2003 at an air temperature of $20.6^{\circ} \mathrm{C}$. other Anodonthyla species, calls of A. emilei are unique in being grouped to clearly defined short series, whereas calls of other species are usually very long regular continuous series, lasting up to several minutes when males are highly motivated (Glaw and Vences, 2005). Note duration in A. emilei is short and similar to the note duration in A. moramora, A. boulengeri and A. nigrigularis, whereas notes of $A$. theoi and A. vallani are longer. The comparatively low dominant frequency in A. emilei calls is shared only by A. vallani, whereas known calls of the other species have higher dominant frequencies (Table 3).

Natural history. Calling males from A. emile $i$ were found at night, calling from tree trunks $2-3 \mathrm{~m}$ above the ground, and in one case from inside a tree hole with a very small entrance, about $1.5 \mathrm{~m}$ above the ground. One specimen (ZSM 369/2004) was found together with eggs inside a tree hole.

Distribution. The species is only known from Ranomafana National Park where we found it at two 
localities, Samalaotra and Maharira. Especially at Maharira the species was not rare and its characteristic calls were commonly heard, but at several other sites in and around Ranomafana we did not record the species despite intensive fieldwork.

\section{Anodonthyla theoi sp. nov. (Fig. 12)}

Holotype. ZSM 2275/2007 (field number ZCMV 5463), adult male, collected at a site in the part of Manombo Special Reserve west of the main road (coordinates not taken, but not far from our campsite at $23^{\circ} 01.699^{\prime} \mathrm{S}$, 4743.892' E, $44 \mathrm{~m}$ a.s.1.), Fianarantsoa Province, South East of Madagascar, on 24 February 2007 by M. Vences, G. Safarek, E. Rajeriarison and T. Rajofiarison.

Paratypes. ZSM 2273/2007 (ZCMV 5454), ZFMK 89186 (=ZSM 2274/2007 [ZCMV 5499]), two adult males, and UADBA uncatalogued (ZCMV 5465 and 5498), two specimens, all with same data as holotype; ZSM 2276/2007 (ZCMV 5468), one adult male, collected at a second site in Manombo Special Reserve (coordinates not taken, but ca. $1 \mathrm{~km}$ south of type locality), Fianarantsoa Province, on 23 February 2007 by M. Vences, G. Safarek, E. Rajeriarison and T. Rajofiarison.

Justification. This species appears to be phylogenetically related to A. pollicaris which however strongly differs in note repetition rate. $16 \mathrm{~S}$ divergences of $A$. theoi are high: $3.5 \%$ to A. pollicaris and $7.9-11.8 \%$ to other Anodonthyla. Detailed analysis shows that those species with similar note repetition rates (A. moramora and $A$. vallani described below) differ by other call characters. This situation clearly indicates that $A$. theo $i$ is a separate and well-defined species.

Diagnosis. A small arboreal frog assigned to Anodonthyla on the basis of the presence of a distinct prepollex in males. Distinguished from all other Anodonthyla by a significant genetic differentiation. A. theoi is further distinguished from A. montana, A. rouxae and A. emilei by smaller size (male SVL 18-20 vs. $24-34 \mathrm{~mm}$ ), and from A. rouxae by the absence of distinct humeral spines in males (vs. presence). Furthermore distinguished from A. boulengeri, A. pollicaris, A. sp.aff. boulengeri 'Ranomafana', A. hutchiso$n i$, and $A$. nigrigularis by a lower note repetition rate (0.8-0.9 vs. 1.0-3.1 per second), and from A. moramo$r a$ by longer note duration in advertisement calls (153230 vs. $47-80 \mathrm{~ms}$ ). Also distinguished from A. moramora by larger body size (male SVL $18-20$ vs. 15-17 $\mathrm{mm}$ ) and absence of greenish shade of dorsal and ventral colour (vs. presence in many specimens in life), and from most specimens of A. boulengeri, A. polli- caris and A. sp. aff. boulengeri 'Ranomafana' by a blackish vocal sac of males.

Description of holotype. Specimen in reasonably good state of preservation (muscle tissue from left thigh removed as tissue sample for molecular analysis, skin removed from right thigh, body cavity opened for parasitological study). SVL $18.9 \mathrm{~mm}$ (for other measurements see Table 2). Body moderately slender; head slightly wider than long, not wider than body; snout rounded in dorsal and lateral views; nostrils directed laterally, slightly protuberant, of same distance to tip of snout and to eye; canthus rostralis indistinct, concave; loreal region straight; tympanum indistinct, rounded, its diameter $48 \%$ of eye diameter; supratympanic fold indistinct; tongue ovoid, posteriorly broader than anteriorly, free and not notched or forked; small maxillary teeth present; vomerine teeth absent; choanae rounded. Arms strongly thickened; subarticular tubercles poorly recognizable at the base of fingers; outer metacarpal tubercle indistinct; prepollex medium-sized and distinct, extending from the area generally occupied by the inner metacarpal tubercle to a point below digital pad of first finger; tips of first finger and prepollex diverging; fingers without webbing; relative length of fingers $1<2<4<3$, inner finger rudimentary, with roundish, slightly enlarged disk, disks of fingers 2-4 distinctly enlarged, of triangular shape; keratinized nuptial pads absent, but a distinctly thickened unpigmented area on inner side of lower arm. Hindlimbs slender; tibiotarsal articulation reaching between forelimb insertion and tympanum when hindlimb adpressed along body; TL $43 \%$ of SVL; lateral metatarsalia strongly connected; metatarsal tubercles poorly recognizable; no webbing between toes; relative length of toes $1<2<5<3<4$; third toe distinctly longer than fifth. Skin on dorsum and ventral surface smooth.

Colour. After two years in preservative, dorsum marbled grey and brown with small blackish dots and with oval light spots on each side of the back. Posterior head dark brown. A strong colour border between the eyes, colouration of anterior head light brown. A small black spot on each side above the tympanic region. Each forelimb with one distinct dark crossband, hindlimbs with several dark crossbands. Throat blackish, chest dark brown, belly and (remaining) ventral skin of the hindlimbs light brown, thickened ventral sides of arms unpigmented. For colour in life see Fig. 12.

Variation. Only the three male paratypes deposited in ZSM were available for comparison. They all share with the holotype the colour border between the eyes, the black spot in the tympanic region, the presence of 
a distinct dark crossband on the lower arm just above the hand, and a dark throat. The dark crossbands on the hindlimbs and the contrasted dorsal pattern are much less distinct though recognizable in ZSM 2276/2007 and ZSM 2273/2007. The three paratypes have a dark $\mathrm{W}$-shaped marking in the neck that is very indistinct and not clearly recognizable in the holotype. Furthermore, they share 3-4 dark spots arranged across the mid-dorsum which correspond to dermal elevations in ZFMK 89186) and lack the pair of light oval spots at middorsum which are clearly recognizable in the holotype. The arms of the paratypes are less thickened compared with the holotype.

Etymology. This species is dedicated to Theophilus ('Theo') Rajoafiarison, nature guide at Ranomafana National Park (and Emile's brother) who provided invaluable help during the collection of this new species at Manombo Special Reserve.

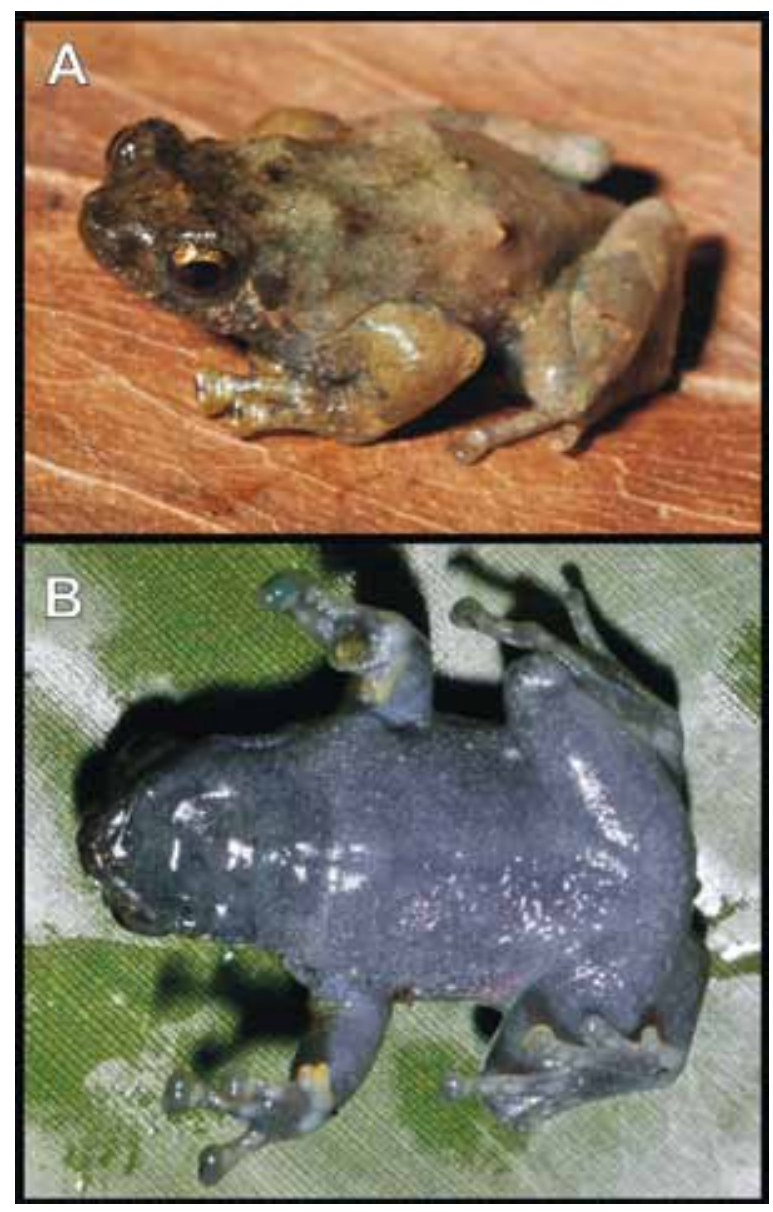

Fig. 12. Living specimen of Anodonthyla theoi from Manombo Special Reserve in (A) dorsolateral and (B) ventral views. Photos by Goran Safarek.
Advertisement call. Vocalization was recorded on 23 February 2007 at about 19:00 h (air temperature unknown) at Manombo, from paratype specimen ZSM 2276/2007. The advertisement call (Figs 4 and 13) consists of a moderately long note of $153-230 \mathrm{~ms}$ duration, repeated at regular intervals at a rate of only 0.8-0.9 notes/second. Intervals between notes range from $880-1297 \mathrm{~ms}(\mathrm{~N}=11)$. If highly motivated and undisturbed, males emitted long series of notes, lasting several minutes. Notes sound melodious, but appear to be of pulsatile nature in the oscillogram, although pulses within notes are not clearly separated. Amplitude modulation within notes is obvious, with an initial increase of energy, reaching its maximum within the first third of the note's duration, subsequently dropping rapidly to a lower level. Dominant frequency of notes is $6040-6100 \mathrm{~Hz}$, additional call energy is present in a narrow frequency band at approximately $9200 \mathrm{~Hz}$. Compared to known calls of other Anodonthyla species, calls of $A$. theoi are characterized by high dominant frequency and relatively long note duration. A comparably high dominant frequency is present in calls of A. moramora, but note duration is shorter and repetition rate of notes is even lower compared to $A$. theoi. Similar note duration is shared by $A$. vallani and $A$. theoi, but the frequency in calls of $A$. vallani is much lower (Table 3 ).

Natural history. Calling males of A. theoi were heard at night from tree trunks, at perch heights 2-3 m above the ground.

Distribution. The species is only known from Manombo Special Reserve. Calling males in the reserve were very commonly heard.

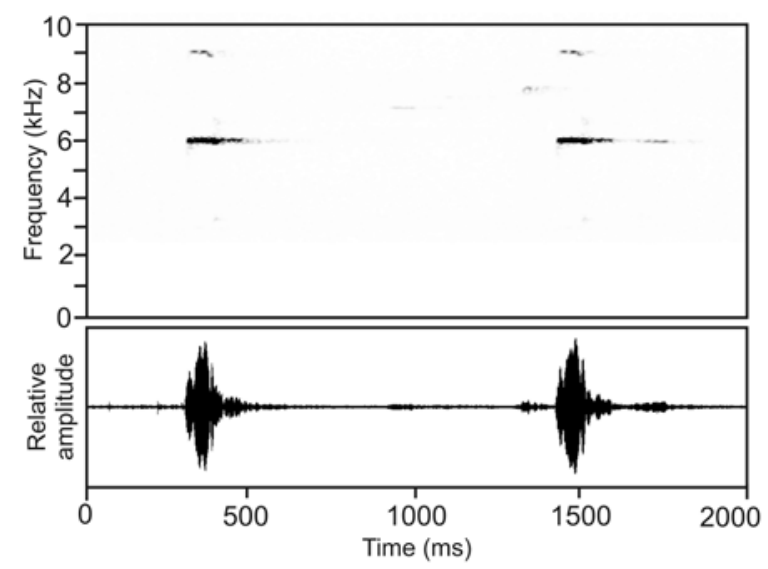

Fig. 13. Spectrogram and waveform of a part of a call series of Anodonthyla theoi, recorded from paratype ZSM 2276/2007 at Manombo Special Reserve on 23 February 2007. 
Anodonthyla vallani sp. nov. (Fig. 14a-b)

Holotype. ZSM 86/2005 (field number FGZC 2102), adult male, collected at Ambohitantely Special Reserve, forest near camp, 0.5-1 km from: $18^{\circ} 11.967 ' \mathrm{~S}$, $47^{\circ} 16.853^{\prime} \mathrm{E}$, ca. $1580 \mathrm{~m}$ a.s.l., Antananarivo Province, central Madagascar, on 17 January 2005 by M. Vences, L. du Preez, P. Bora, L. Raharivololoniaina, R. D. Randrianiaina, T. Razafindraibe and E. Randriamitso.

Paratype. ZSM 87/2005 (field number FGZC 2103), adult male, same data as holotype.

Justification. This species appears to be phylogenetically related to $A$. sp. aff. boulengeri 'Ranomafana' which however strongly differs in note repetition rate and is also morphologically different. $16 \mathrm{~S}$ divergences of $A$. vallani to all other Anodonthyla are very high: $9.0 \%$ to $A$. sp. aff. boulengeri 'Ranomafana' and 9.7-11.4\% to other Anodonthyla. Detailed analysis (see below) shows that those species with similar note repetition rates ( $A$. theoi and $A$. moramora) differ by other call characters. This situation clearly indicates that $A$. vallani is a separate and well-defined speciesDiagnosis. A comparatively medium-sized arboreal frog assigned to Anodonthyla on the basis of the presence of a distinct prepollex in males. Distinguished from all other Anodonthyla by a significant genetic differentiation. A. vallani is further distinguished from A. montana by smaller size (male SVL 23-24 vs. 32-34 $\mathrm{mm}$ ) and a less strongly developed supratympanic fold; from A. rouxae by the absence of distinct humeral spines in males (vs. presence) and generally by the presence of some coarse tubercles on body (vs. smooth skin). Furthermore distinguished from A. boulengeri, A. pollicaris, and A. sp. aff. boulengeri 'Ranomafana' by a slower note repetition rate (0.8-1.0 vs. 1.8-3.1 notes/second), and from A. moramora by longer note duration in advertisement calls (154-236 vs. $47-80 \mathrm{~ms}$ ). Also distinguished from A. boulengeri, A. pollicaris, A. sp. aff. boulengeri 'Ranomafana', $A$. moramora, A. theoi, and A. nigrigularis by larger body size (male SVL 23-24 vs. $15-22 \mathrm{~mm}$, up to 22.6 $\mathrm{mm}$ in one A. boulengeri), and from A. moramora by the absence of greenish shade of dorsal and ventral colour (vs. presence in many specimens in life), and from most specimens of A. boulengeri, A. pollicaris and $A$. sp. aff. boulengeri 'Ranomafana' by a blackish vocal sac of males. The calls of $A$. vallani are most similar to those of $A$. theoi in their temporal characters, but strongly differ in the dominant frequency (2850-2900 vs. 6040-6100 Hz).

Description of holotype. Specimen in excellent state of preservation (muscle tissue from left thigh removed as tissue sample for molecular analysis). SVL $22.8 \mathrm{~mm}$ (for other measurements see Table 2). Body moderately slender; head wider than long, not wider than body; snout rounded in dorsal and lateral views; nostrils directed laterally, slightly protuberant, of same distance to tip of snout and to eye; canthus rostralis poorly distinct, concave; loreal region straight; tympanum indistinct, rounded, its diameter $48 \%$ of eye diameter; supratympanic fold moderately distinct; tongue ovoid, posteriorly broader than anteriorly, free and not notched or forked; small maxillary teeth present; vomerine teeth absent; choanae rounded. Arms moderately thickened; subarticular tubercles recognizable at the base of fingers; outer metacarpal tubercle indistinct; prepollex medium-sized and distinct, extending from the area generally occupied by the inner metacarpal tubercle to a point below digital pad of first finger; tips of first finger and prepollex slightly diverging; fingers without webbing; relative length of fingers $1<2 \leq 4<3$, inner finger very rudimentary with roundish, slightly enlarged disk, disks of fingers 2-4 distinctly enlarged, of triangular shape; nuptial pads absent. Hindlimbs slender; tibiotarsal articulation reaching the tympanum when hindlimb adpressed along body; TL $47 \%$ of SVL; lateral metatarsalia strongly connected; metatarsal tubercles poorly recognizable; no webbing between toes; relative length of toes $1<2<5<3<4$; third toe distinctly longer than fifth. Skin on dorsum and ventral surface smooth.

Colour. After four years in preservative, dorsum almost uniformly dark brown with poorly recognizable dark markings and a distinct beige marking between the eyes. Head sides including tympanic region blackish. Each forelimb with one distinct dark crossband, hindlimbs with several dark crossbands. Throat blackish, chest dark brown, belly and ventral side of arms and legs brown with whitish dots. In life, dorsum dark brown with some lighter brown on posterior parts. Dorsal surfaces of arms brown, those of legs dark brown with some indistinct irregular light brown bars, posterior surfaces of thighs with irregular cream flecks. Broad cream stripe between eyes, medially extending slightly on snout, and posteriorly bordered by dark brown. Tympanic region blackish. Ventral surfaces pinkish white, covered by some violet-brown marbling, scattered with irregular small white spots, throat blackish with few scattered minute white spots. Palmar and plantar surfaces blackish brown with white tubercles. Iris bronze with some irregular black flecking. 


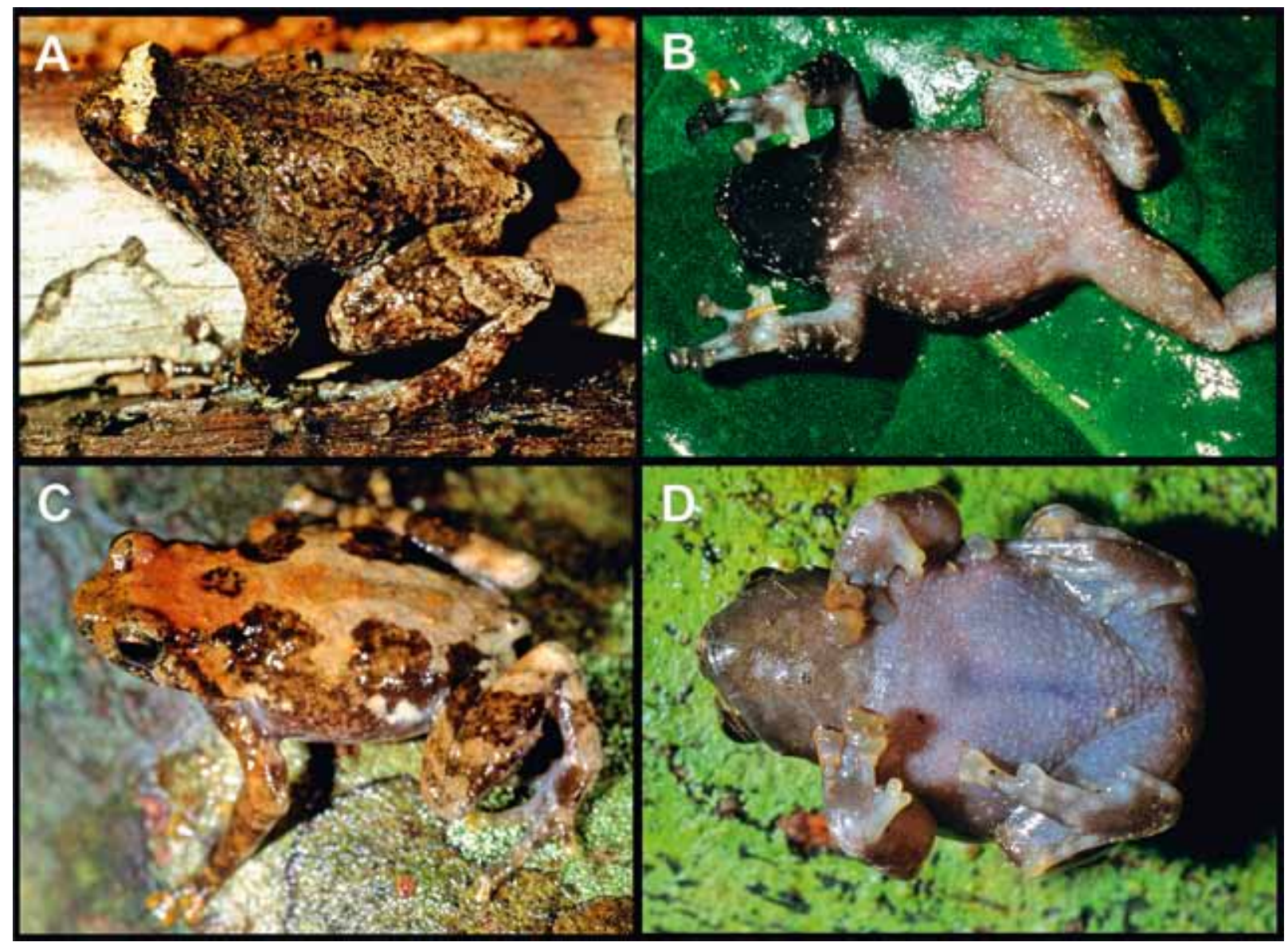

Fig. 14a-d. Specimens of Anodonthyla vallani and A. nigrigularis in life (all males). (A-B) Holotype specimen ZSM 86/2005 of A. vallani in dorsolateral and ventral views; (C-D) A. nigrigularis specimen ZSM 88/2004 from Andohahela National Park (between Isaka and Eminiminy) in dorsolateral and ventral views.

Variation. The second known specimen (paratype ZSM 87/2005) differs only very slightly from the holotype. The general colour pattern is identical, with the paratype exhibiting a slightly darker dorsum in preservative and with the pale stripe between the eyes being slightly narrower. For measurements see Table 2.

Etymology. Dedicated to our friend and colleague Denis Vallan in recognition of his pioneering work on the effects of forest fragmentation on amphibian communities at the type locality of this new species, Ambohitantely Special Reserve.

Advertisement call. Vocalization was recorded from the holotype on 17 January 2005 at about 20:00 h (air temperature unknown) at Ambohitantely Special Reserve (Vences et al., 2006, CD 3, track 73). The advertisement call (Figs 4, 15) consists of a moderately long melodious, but apparently pulsatile note of 154-236 ms

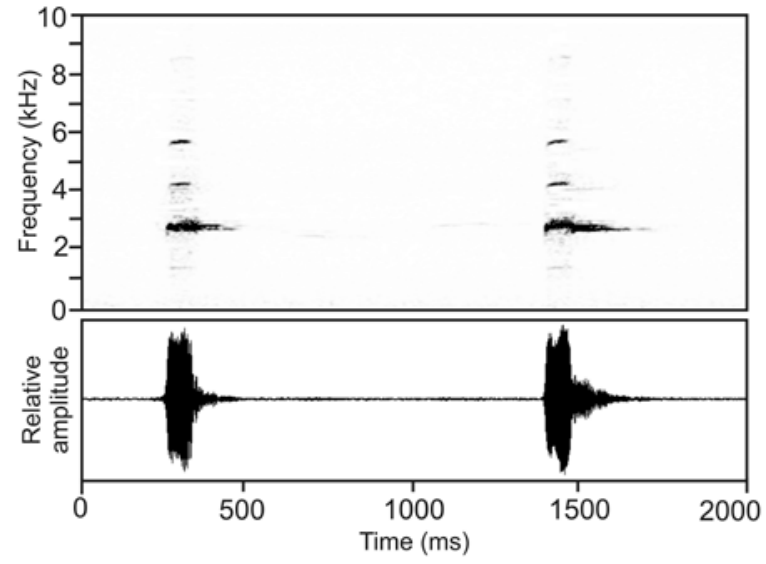

Fig. 15. Spectrogram and waveforms of a part of a call series of the holotype of Anodonthyla vallani, recorded at Ambohitantely Special Reserve on 17 January 2005. 
duration, repeated at relatively regular intervals at a rate of only 0.8-1.0 notes/second. Intervals between notes range from 705-1016 $\mathrm{ms}(\mathrm{N}=14)$. If highly motivated and undisturbed, males emitted long series of notes, lasting several minutes. Notes exhibit some amplitude modulation, with a distinct decrease of intensity from the middle of the note towards its end. Dominant frequency of notes is $2850-2900 \mathrm{~Hz}$, additional call energy is present in two frequency bands at approximately 4370 and $5800 \mathrm{~Hz}$. Compared to known calls of other Anodonthyla species, calls of A. vallani are characterized by relatively long note duration, shared only with calls of A. theoi. Although very similar in note duration and note repetition rate, calls of the two mentioned species can easily be distinguished by frequency parameters, as the dominant frequency in A. theoi is 6040-6100 $\mathrm{Hz}$, and thus more than double the value measured for A. vallani. Calls of other Anodonthyla species differ at least by shorter note duration (see Table 3 ).

Natural history. Males of $A$. vallani were observed calling at night, including nights with relatively dry weather when few other frogs were calling, from tree trunks at heights of 2-3 m.

Distribution. The species is only known from Ambohitantely Special Reserve. Calling males were very commonly heard at different sites in the reserve.

\section{Anodonthyla jeanbai sp. nov. (Fig. 16)}

Holotype. ZSM 88/2005 (field number FGZC 2405), adult male, collected at Andohahela National Park, near our campsite that was located at $24^{\circ} 32.642^{\prime} \mathrm{S}$, 46 $42.847^{\prime} \mathrm{E}, 1548 \mathrm{~m}$ a.s.l., Toliara Province, southeastern Madagascar on 27 January 2005 by P. Bora, F. Glaw and M. Vences.

Paratypes. ZSM 89-96/2005 (field numbers FGZC $2406,2407,2409,2411,2414,2416,2418,2419)$ and ZFMK 89187 (=ZSM 97/2005, field number FGZC 2421), six males and three females (see Table 2), all with same data as holotype, and UADBA uncatalogued (FGZC 2408, 2410, 2412, 2413, 2415, 2417, 2420), seven specimens, same data as holotype.

Justification. The phylogenetic tree indicates that $A$. jeanbai has a very isolated phylogenetic position, without clear relationships to any other Anodonthyla. Its genetic $16 \mathrm{~S}$ divergence to other species is 9.4$12.1 \%$. Although we have no data on the advertisement call of A. jeanbai, we consider this high genetic divergence in concert with various diagnostic morphological characters as given below to be clearly indicative of its species status.
Diagnosis. A small arboreal frog assigned to Anodonthyla on the basis of the presence of a distinct prepollex in males. Distinguished from all other Anodonthyla by a significant genetic differentiation. $A$. jeanbai is further distinguished from A. montana, $A$. emilei, A. vallani, and from the syntopic $A$. rouxae by smaller size (male SVL $14-20$ vs. $23-34 \mathrm{~mm}$ ), and from A. rouxae by the absence of distinct humeral spines in males (vs. presence). A difference visible in living A. jeanbai and absent from all other Anodonthy$l a$ is a short tuberculous fold running from directly behind the eye, slightly bent towards the center of the dorsum, and ending at the level of the forelimb insertion (sometimes continuing along the dorsum; in preserved specimens, this ridge often is only poorly recognizable). Additionally, in A. jeanbai the first finger is extremely reduced and in most specimens is not considerably longer than the prepollex. A. jeanbai is furthermore distinguished from all Anodonthyla, except $A$. moramora, by the presence of a yellowish pigment on ventral surfaces in life, sometimes completely extending over the venter, or just some yellow pigment on the belly; in A. moramora, the venter often has a greenish shade in life that could be mistaken with the yellow pigment of $A$. jeanbai whereas other species have greyish, white and black colours on the venter only. A. jeanbai furthermore differs by its very distinct tympanum from various other species where the tympanum is often less clearly visible, and by a comparatively long and narrow head (average ratio HW/HL 0.95 , range $0.86-0.98$, vs. usually $>0.95$ and often $>1$ in all other species). Also distinguished from most specimens of $A$. nigrigularis, $A$. theoi and A. vallani by the absence of a blackish vocal sac in males (vs. presence).

Description of holotype. Specimen in good state of preservation (muscle tissue from right thigh removed as tissue sample for molecular analysis). SVL 19.9 $\mathrm{mm}$ (for other measurements see Table 2). Body slender; head slightly longer than wide, not wider than body; snout slightly pointed in dorsal view, rounded in lateral views; nostrils directed laterally, slightly protuberant, of same distance to tip of snout and to eye; canthus rostralis indistinct, concave; loreal region straight; tympanum distinct, rounded, its diameter $67 \%$ of eye diameter; supratympanic fold clearly recognizable; tongue ovoid, posteriorly broader than anteriorly, free and not notched or forked; small maxillary teeth poorly recognizable; vomerine teeth absent; choanae rounded. Arms moderately thickened; subarticular tubercles well recognizable at the base of 


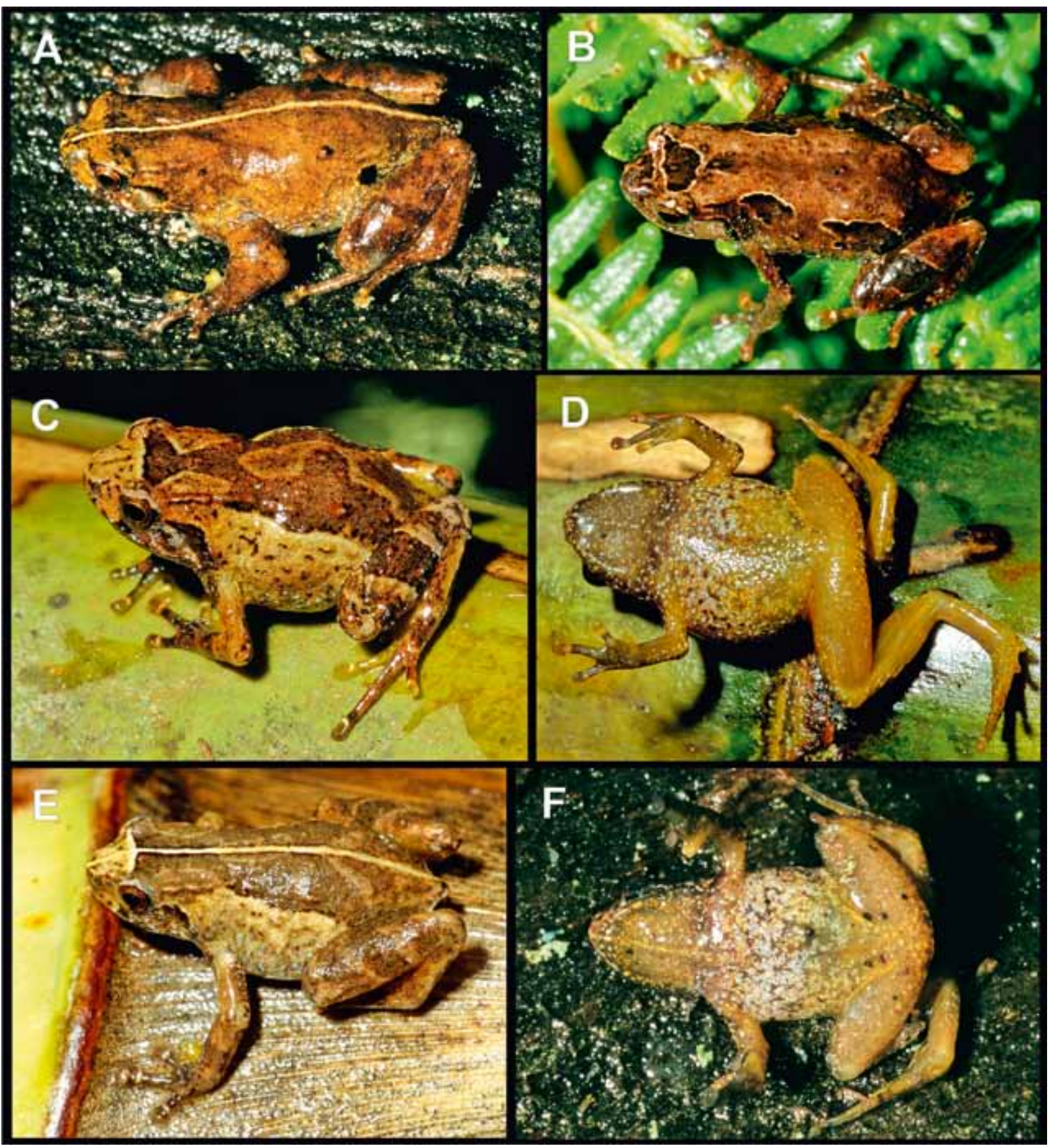

Fig. 16a-f. Specimens of Anodonthyla jeanbai in life, in dorsolateral and ventral views, all from Andohahela National Park. (A) Holotype specimen ZSM 88/2005; (B-F) paratype specimens, all preserved in the UADBA collection.

fingers; outer metacarpal tubercle distinct; prepollex distinct, extending from the area generally occupied by the inner metacarpal tubercle to the tip of the first finger; tips of first finger and prepollex slightly diverging; fingers without webbing; relative length of fingers $1<2<4<3$, inner finger extremely rudimentary with roundish, rudi- mentary disk, disks of fingers 2-4 distinctly enlarged, of triangular shape; keratinized nuptial pads absent, but a distinctly thickened unpigmented area on inner side of arm. Hindlimbs slender; tibiotarsal articulation reaching tympanum when hindlimb adpressed along body; TL $42 \%$ of SVL; lateral metatarsalia strongly connected; 
Fig. 17a-b. Specimens of Anodonthyla rouxae and A. montana in life in dorsolateral views. (A) Male of A. rouxae from Andohahela National Park (ZSM 98/2005); (B) specimen of Anodonthyla montana from Andringitra National Park. Arrow in A points at the humeral spine typical for A. rouxae.

metatarsal tubercles poorly recognizable; no webbing between toes; relative length of toes $1<2<5<3<4$; third toe distinctly longer than fifth. Skin on dorsum and ventral surface smooth.

Colour. After two years in preservative, dorsum and posterior part of head almost uniformly brown, anterior head slightly lighter brown. A thin $(<0.5 \mathrm{~mm})$ light middorsal line from snout tip to cloaca. Two black spots in the inguinal region. Tympanic region light, bordered by a dark supratympanic fold. Forelimbs without distinct dark crossbands, hindlimbs with distinct dark crossbands. Cloacal region blackish. Throat, chest and ventral parts of limbs dirty yellowish with scattered brown pigment and small whitish dots; belly similarly coloured but more greyish. Thickened ventral sides of arms unpigmented.

In life, dorsum light brown with some very indistinct irregular brown flecking, pale colour covering
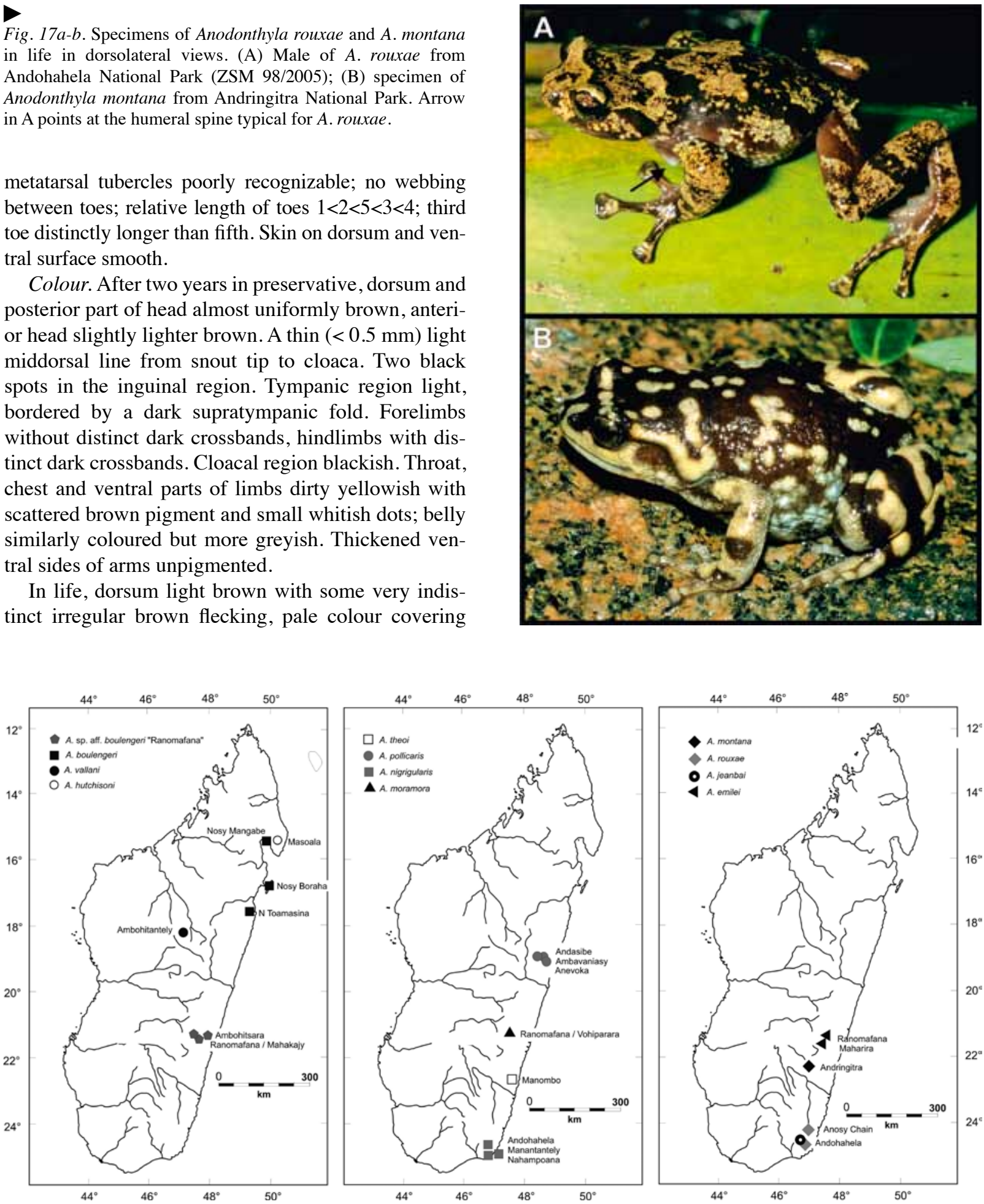

Fig. 18. Maps summarizing the reliably known distribution records of species of Anodonthyla. Several additional records are available for A. boulengeri (e.g. Blommers-Schlösser and Blanc, 1991; Glaw and Vences, 2007) and for A. montana but are not backed by bioacoustic or molecular data. Note that the positioning of the symbols on the map is approximative; especially when localities are very close to each other, symbols are partly placed slightly more away from each other to allow a better recognition. 
snout and extending posteriorly to interorbital region, narrow cream vertebral line, extending from cloaca to tip of snout, black oval fleck in groin, smaller irregular black spot lateral in scapular region and on posterior dorsum. Dorsal surfaces of arms and legs light reddish brown with some indistinct irregular darker markings. Ventral colouration in life unknown. Iris bronze with fine black spotting.

Variation. A. jeanbai is a highly polychromatic species. As shown in Fig. 16, the colour pattern might differ considerably, with specimens exhibiting a vertebral stripe and others lacking it. Some specimens have a brown dorsal colouration with dark brown flecks encircled by thin cream lines (Fig. 16e). Many specimens exhibit a more or less regular dark 'hourglass' pattern in the scapular region and/or small reddish brown tubercles scattered on dorsum. Larger dark markings might be present on different dorsal body parts. However, all specimens exhibit a yellowish tint on ventral surfaces of limbs and posterior belly, and a tuberculous fold extending from the eye posteriorly to the level of insertion of forearm. Measurements are provided in Table 2.

Etymology. We dedicate this new species to the Malagasy herpetologist Jean Baptiste (Jean-Ba) Ramanamanjato who provided logistic information that proved to be crucial for the success of our expedition to the type locality, at higher elevations in Andohahela National Park.

Natural history. Specimens were found at one single site, a forest with high bamboo density at higher elevations. Specimens were very common and were found at night 1-2 m high on bamboo trunks, but no cophyline calls were heard during the single night of survey at this site. The species occurred in close syntopy with A. rouxae which appeared to be rarer, with only three specimens found at this site.

Distribution. The species is only known from one surveyed site at higher elevation in Andohahela National Park.
New data on other Anodonthyla species

\section{Anodonthyla hutchisoni}

This is the only species of Anodonthyla not included in our own collections. Fenolio et al. (2007) tentatively assigned a specimen from Nosy Mangabe to this species. According to our results, specimens from Nosy Mangabe however belong to A. boulengeri. Because on that island we have never heard calls with the slow note repetition rate apparently typical for A. hutchiso$n i$, and because specimens of $A$. boulengeri from this locality are characterized by a relatively large body size as otherwise typical for A. hutchisoni, we conclude that so far there are no reliable records of $A$. hutchisoni from Nosy Mangabe.

\section{Anodonthyla nigrigularis (Fig. 14c-d)}

Newly recorded calls of A. nigrigularis from Manantantely agree with previously published recordings for the species (Table 3, Fig. 4). The same is true for an additional recording from Andohahela National Park (between Isaka and Eminiminy), recorded on 3 February $2004\left(23.2^{\circ} \mathrm{C}\right)$. Despite the poor quality of this latter recording, some call parameters could be determined (not included in Table 3): dominant frequency $4400 \mathrm{~Hz}$; note duration 75-90 ms, ca. $900 \mathrm{~ms}$ internote interval, repetition rate ca. 1 note/second.

\section{Anodonthyla rouxae (Fig. 17a)}

During a survey at higher elevations of Andohahela National Park we could find two males and one subadult specimen of this species, in an area with high density of bamboo, within primary rainforest, and syntopic with A. jeanbai. Both adult specimens had conspicuous humeral spines which, within Anodonthyla, appear to be an autapomorphy of $A$. rouxae (see also Guibé 1978). One of the collected specimens (ZSM 98/2005) had a SVL of $33.9 \mathrm{~mm}$, representing the largest known male of this species. 